\title{
IFS
}

\section{THE DYNAMICS OF INVESTMENT UNDER} UNCERTAINTY

\author{
Nicholas Bloom \\ Stephen Bond \\ John Van Reenen
}




\title{
The Dynamics of Investment under Uncertainty
}

\author{
Nicholas Bloom*, Stephen Bond ${ }^{\dagger}$ and John Van Reenen
}

February 2001

\begin{abstract}
We derive robust predictions on the effects of uncertainty on short run investment dynamics in a broad class of models with (partial) irreversibility. When their environment becomes more uncertain firms become more cautious and less responsive to demand shocks. This result contrasts with the long run analysis, in which the effect of real options on the level of the capital stock is ambiguous. An investment model is estimated to test these theoretical predictions using a panel of UK firms and a stock returns-based measure of uncertainty. As predicted we find that uncertainty reduces firms' responsiveness to demand shocks.
\end{abstract}

Keywords: Investment, uncertainty, real options, panel data

JEL Classification: D92, E22, D8, C23.

Acknowledgments: The authors would like to thank Jerome Adda, Manuel Arellano, Orazio Attanasio, Richard Blundell, Jason Cummins, Janice Eberly, Domenico Lombardi, Costas Meghir, Ian Preston, Isabel Reduto dos Reis, Helen Weeds and Frank Windmeijer. This research is part of the program of research at the ESRC Centre for the Micro-Economic Analysis of Fiscal Policy at the IFS. Financial support of the ESRC is gratefully acknowledged.

Correspondence: nick.bloom@ifs.org.uk; 7 Ridgmount Street, London WC1E 7AE, UK.

\footnotetext{
*Institute for Fiscal Studies and University College London

$\dagger$ Institute for Fiscal Studies and Nuffield College, Oxford

${ }$ CEPR, Institute for Fiscal Studies and University College London
} 


\section{Introduction}

The standard approach to modelling investment under uncertainty considers a firm operating a single production process and using a homogeneous capital good ${ }^{1}$. Investment decisions are assumed to be (partially) irreversible and market demand uncertain. This generates real options on the investment decision and a separation of the thresholds for investment and disinvestment, with no investment undertaken in between these thresholds. Even low levels of uncertainty and irreversibility can lead these thresholds to be significantly spaced apart in relation to their positions under complete certainty and costless reversibility, changing the optimal investment behaviour of firms from being smooth and continuous to one that is lumpy and frequently zero.

At first sight firm-level investment series appear too smooth to be consistent with these models of investment under uncertainty. But in micro establishmentlevel data, like the US Longitudinal Research Database (LRD) and the UK Annual Respondents' Database (ARD), such lumpy investment with frequent zeros is observed, particularly for smaller plants ${ }^{2}$. This suggests that observations with zero investment at the firm level occur infrequently simply because of aggregation across multiple investment decisions. This is not surprising - firms are often observed to operate multiple production lines, plants and subsidiaries, each employing many types of capital goods. If these processes are not perfectly correlated due to idiosyncratic shocks and heterogeneous technologies then aggregation will smooth away much of the lumpiness from a firm-level series for total investment.

\footnotetext{
${ }^{1}$ See Bertola (1988), Pindyck(1988) and Dixit and Pindyck (1994), for example.

${ }^{2}$ See Doms and Dunne (1998) for the US, Attanasio et al (2000) for the UK, and Anti Nilsen and Schiantarelli (1998) for Norway.
} 
Nevertheless uncertainty will still play an important role in determining firm-level investment through its effects on the investment decisions for the individual types of capital. This has been shown in a number of papers on macro investment and consumption which demonstrate that aggregation does not diminish the effects of lumpy micro level behaviour ${ }^{3}$.

We develop a theoretical approach which identifies some robust predictions on firm-level investment dynamics which can be recovered after aggregation across multiple capital inputs, and we test these predictions empirically using firm-level panel data. Our main prediction is that uncertainty does play an important role in determining the short run response of investment to changes in market demand, whether or not uncertainty has any effect on the level of the capital stock in the longer term. Higher levels of uncertainty increase the real option values associated with investment and disinvestment and so make firms more cautious in responding to changes in their market environment. The presence of (partial) irreversibility and uncertainty also leads to non-linear investment dynamics with an increasing marginal investment response to larger demand shocks. This is potentially important because the dynamic response of firms to tax incentives and interest rates will depend on the uncertainty in their environment and the size of the stimulus. Since uncertainty and demand shocks have important cross sectional and time series variability, this also provides a possible explanation for the parameter instability within and across samples that has often been reported in the context of empirical investment equations.

Since the modelling strategy of this paper is to derive robust predictions on

\footnotetext{
${ }^{3}$ See, for example, Caballero (1993) and Eberly (1994) on aggregation across consumer durables, and Bertola and Caballero (1994), Caballero and Engel (1999), Cooper et al. (2000) and Attanasio et al. (2000) on aggregation across plant level investment
} 
firm-level investment behaviour, we avoid making strong assumptions about the nature of production functions or the firm's demand environment. Our underlying model encompasses a wide class of production functions and stochastic processes, and nests the standard Cobb-Douglas and Brownian motion assumptions found in the investment literature. This generality does not lead to a closed form analytical result but does provide a broad characterisation of investment behaviour. Using this framework we also demonstrate an important result for our empirical investigation - that a temporary increase in uncertainty increases the distance between the investment and disinvestment thresholds.

We test these predictions empirically using firm-level panel data and GMM estimates of dynamic investment equations. The firm level is attractive relative to the plant level in that we observe useful measures of uncertainty, and relative to the macro level in that we observe significant variation across firms in the level of uncertainty. Our theory suggests that higher uncertainty will reduce the response of firms to demand shocks. We add an additional interaction term between uncertainty and sales growth to our firm-level investment equations to test for this 'caution effect' of uncertainty and its role in generating time and firm varying investment parameters. We find this interaction term to be highly significant in our empirical analysis. In addition, we also include a quadratic term in sales growth to test for the predicted non-linear response of investment to demand shocks, and again find this to be highly significant. We also generate an artificial panel by simulating our theoretical model, and confirm that these theoretical predictions are detected by our estimation strategy applied to the simulated data. 
The plan of the paper is as follows. Section 2 introduces the standard single line of capital model of investment under uncertainty and discusses the threshold behaviour this implies. In section 2.2 this is generalised to a multiple capital goods model with more general demand shocks. Section 2.3 introduces a new result on the impact of a temporary increase in the level of uncertainty, which temporarily increases the gap between the investment and disinvestment thresholds. Section 2.4 discusses aggregation over production plants to the level of total firm investment, and develops a second order approximation to the resulting investment behaviour. Our empirical strategy is outlined in section 3 and our investigation of the properties of this strategy using simulated data is discussed. Section 4 discusses the uncertainty measure and firm-level data, while section 5 reports our main empirical results and evaluates the quantitative impact of uncertainty on investment dynamics. Some concluding remarks are made in section 6 . Technical and data appendices then follow.

\section{Modelling Investment Under Uncertainty}

The literature on investment under uncertainty predicts threshold investment behaviour ${ }^{4}$. Abel and Eberly (1996) examine a model of partial irreversibility and demonstrate that the solution to this can be fully characterized in terms of the firm's concentrated marginal revenue product of capital ${ }^{5}, P^{1-a} K^{a-1}$ - where $P$ is a demand term, $K$ is capital and $0<a<1-$ and its lower disinvestment and

\footnotetext{
${ }^{4}$ See, for example, Pindyck (1988) for fully irreversible continuous investment, Dixit (1989) for partially irreversible discrete investment, Bertola and Caballero (1994) for investment with stochastic demand and capital prices and Dixit and Pindyck (1994) for a general survey of the literature.

${ }^{5}$ Labour and other inputs, which are assumed to be fully flexible in this model, have been optimised out of the concentrated marginal revenue product of capital.
} 
upper investment thresholds. These investment thresholds can be represented by the standard Jorgensonian user cost of capital for buying and selling capital, $b$ and $s$ respectively $^{6}$, an investment real options term $\phi_{I}>1$, and a disinvestment real options term $\phi_{D}>1$. Investment only takes place when the marginal revenue product of capital hits the upper threshold and disinvestment only takes place when it hits the lower threshold. This investment policy is summarized in Table 1 below:

Table 1: The threshold behaviour of investment

\begin{tabular}{|l|l|}
\hline Invest if: & $P^{1-a} K^{a-1} \geq b \times \phi_{I}$ \\
\hline Do nothing if: & $s / \phi_{D}<P^{1-a} K^{a-1}<b \times \phi_{I}$ \\
\hline Disinvest if: & $P^{1-a} K^{a-1} \leq s / \phi_{D}$ \\
\hline
\end{tabular}

Firms will undertake sporadic bursts of investment to ensure their capital stock stays between corresponding disinvestment and investment thresholds, with these thresholds being functions of model parameters, such as the degree of uncertainty, irreversibility, and also the current state of demand. Threshold investment and consumption models of this type have already been successfully estimated on a variety of data sets. For example, Caballero, Engel and Haltiwanger (1995), Cooper, Haltiwanger and Power (1999) and Attanasio and Pacelli (2000) estimate threshold investment models on US and UK plant level data, while Eberly (1994) and Attanasio (2000) have estimated threshold models of durable consumption using US car purchasing data ${ }^{7}$.

\footnotetext{
${ }^{6}$ Even under certainty the user cost for buying capital will be above the user cost for selling capital in a partial irreversibility framework where the sale price of capital is assumed to be below the purchase price.

${ }^{7}$ The non-convexities in these papers driving lumpy behaviour and zeros are generally fixed costs rather than partial irreversibilities, which also lead to threshold investment behaviour.
} 


\subsection{A Multi Plant Model of Investment Under Uncertainty}

Investment series for firms and large plants, however, appear to be too smooth and lacking in zero investment observations to be directly consistent with the basic form of the threshold model. Table 2 a reports the frequency of zero investment episodes for annual firm-level data (our sample of quoted UK firms), establishment-level data (a plant or multi-plant production facility from the UK Census of Production), single plant establishment data, and small single plant establishment data (less than 250 employees). There is a clear picture of more frequent zero investment episodes for individual types of capital goods and less aggregated production units. This suggests that aggregation across types of capital goods, production units and production sites obscures the zero investment observations at the firm level, with this aggregation also present in the establishmentlevel data. This is supported by Table $2 \mathrm{~b}$ which displays the frequency of simultaneous investment and disinvestment (capital resale) activities at the firm, establishment and plant level, which again is consistent with aggregation across multiple types of capital even in individual production plants.

Table 2a: Zero Investment Episodes: Frequency ( \%)

\begin{tabular}{|l|l|l|l|l|}
\hline & Buildings \& Land & Plant, Machinery & Vehicles & Total \\
\hline Firms & 5.9 & 0.1 & n.a. & 0.1 \\
\hline Establishments (all plants) & 46.8 & 3.2 & 21.2 & 1.8 \\
\hline Single Plants & 53.0 & 4.3 & 23.6 & 2.4 \\
\hline Small Single Plants & 57.6 & 5.6 & 24.4 & 3.2 \\
\hline
\end{tabular}

Table 2b: Simultaneous Investment \& Disinvestment: Frequency (\%)

\begin{tabular}{|l|l|l|c|}
\hline Firms & Establishments (all plants) & Single Plants & Small Single Plants \\
\hline 99 & 48.0 & 28.2 & 23.3 \\
\hline
\end{tabular}

Notes: Firm-level data (11,098 obs.) from Extel UK and Datastream. Establishmentlevel data (46,089 obs.) from UK ARD Census of Production data (see Reduto dos Reis, 
1999). Single plants (20,907 obs.) are single plant establishments. Small single plants $(15,277$ obs. $)$ are those with less than 250 employees.

Given that firms invest in many kinds of capital goods and may have multiple plants, we need to develop an approach which can deal with this aggregation. This allows us to test for the predicted effects of uncertainty on investment using firm-level panel data, which has a number of advantages, including the provision of a wealth of financial variables, which are not available in establishment or industry-level data. These allow us to control for financial factors such as cash flow and debt. Firm-level data also provide a convenient proxy for uncertainty, in the form of the volatility of the firm's daily share returns, which can be measured on a firm-year basis. The firm level is also often the focus of economic and policy interest in investment, which provides another motivation for using firmlevel data. The empirical procedure we develop, however, could also be applied to other aggregated data sets at the industry or macro level.

To deal with this aggregation we generalise the firm-level production function to allow for $N$ separate lines of capital. These lines of capital could be considered as single production projects in separate locations, operating independently and each employing a single capital input as, for example, in the standard model discussed above. Alternatively these lines of capital might be part of a broader production process employing multiple capital inputs, with operating decisions taken at the more aggregated process level. To deal with this potential ambiguity we define the 'plant' level to be "a production unit for which the solution of the optimisation problem can be identically undertaken at the level of that unit or at 


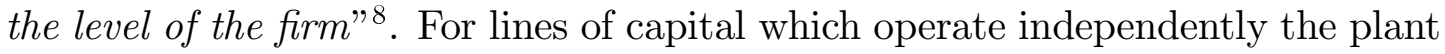
level will be equal to the line of capital level, whilst for lines of capital in multiline production processes the plant will be a larger more aggregated concept. This definition simply allows us to separate the firm's overall production and investment decisions between its individual plants and then aggregate across these.

Production plants are assumed to be subject to productivity and demand shocks which are (at least partly) idiosyncratic, whilst firm-level demand shocks affect all plants within the firm. It will be seen that this results in two distinct types of aggregation taking place:

1. Aggregation across related lines of capital within each production plant, and

2. Aggregation across separate production plants within the firm.

Modelling firm-level investment behaviour then involves a two stage process. In the first step, undertaken in section (2.2), we characterise the nature of optimal investment at the plant level. In the second step, undertaken in section (2.4), we derive the implications for firm-level investment from our characterisation of plant-level investment.

\subsection{Optimal Plant-Level Investment Behaviour}

The general class of plant-level models to which our predictions apply is defined by assumptions (1) to (3) below:

\footnotetext{
${ }^{8}$ An equivalent definition of plants could be made in terms of marginal separability. Plants are defined so that their marginal revenue products of every line of capital employed are separable from lines of capital in other plants. Firms may have between 1 and $\mathrm{N}$ plants. This definition is not really restrictive, since all real-world plants can be considered as one model plant if this separability is not satisfied. Allowing for multiple plants allows us to rationalise firms that simultaneously invest and disinvest in our model.
} 
1. The sales revenue function is continuously differentiable, jointly concave and homogeneous of degree $\lambda$ in all lines of capital, where $\lambda<1$. Whilst $\lambda$ is fixed for plants within the same firm it may vary between firms. Individual lines of capital within each plant are supermodular in production ${ }^{9}$.

2. Adjustment costs are weakly convex and kinked at zero investment due to partial irreversibilities.

3. The firm-level demand shock and the plant-level shocks have a multiplicative impact on sales revenue and are generated by a stationary first order Markov $\operatorname{process}^{10}$.

These conditions encompass a general class of production functions and stochastic processes, for example nesting the standard Cobb-Douglas and Brownian motion approach found in the investment and uncertainty literature and outlined above. Since plants may operate using several types of capital we have to generalise our threshold investment rule from one type of capital to multiple capital inputs. Eberly and Van Mieghem (1997) show that the investment policy of a production plant with $N$ lines of capital satisfying conditions (1) to (3) will be of a multi-dimensional threshold form as characterised in Table 3.

\footnotetext{
${ }^{9}$ Supermodularity is defined such that for a plant-level production function $F\left(K_{1}, K_{2} \ldots K_{N}\right)$ the marginal product of any individual line of capital is increasing in the other lines of capital - that is $\partial F\left(K_{1}, K_{2} \ldots K_{N}\right) / \partial K_{i}$ is increasing in $K_{j} j \neq i$. See also Dixit (1997).

${ }^{10}$ Stationarity implies that this process does not depend on time whilst the first order Markov property implies that only current information is needed for forecasting future demand.
} 
Table 3: $\mathrm{N}$ dimensional threshold investment behaviour

\begin{tabular}{|l|l|}
\hline \multicolumn{2}{|l|}{ For Lines of Capital $i=1,2, \ldots N$} \\
\hline Invest if: & $K_{i} \leq K_{i}^{I}$ \\
\hline Do nothing if: & $K_{i}^{I}<K_{i}<K_{i}^{D}$ \\
\hline Disinvest if: & $K_{i} \geq K_{i}^{D}$ \\
\hline
\end{tabular}

In the absence of depreciation, the most flexible line of capital with the lowest adjustment cost would adjust first to a demand shock, so that its adjustment cost will determine the width of the no-investment threshold for the plant as a whole. Thus infrequently observed investment zeros at the plant level could be consistent with some lines of capital being fully irreversible as long as other lines of capital in the plant are relatively costless to adjust. In the presence of differential depreciation rates this probability of observing zero investment may be even lower since some lines of capital may be near their investment boundaries due to natural depreciation drift.

Hence plant-level investment is smoothed by the aggregation over different lines of capital even though investment in each line of capital may be lumpy and frequently zero. This may explain the relatively smooth nature of investment series with few zeros in establishment-level data such as the US LRD and UK ARD. This aggregation provides one route for firm-level investment dynamics to be smoothed relative to the familiar single project model, even for single plant firms. Before considering aggregation over multiple plants to characterise total firm investment in section (2.4), we first consider the effects of a temporary change in uncertainty on these plant-level investment thresholds. 


\subsection{Effects of Uncertainty and Changes in Uncertainty}

In the case of a single capital input, Abel and Eberly (1996) show that a higher level of uncertainty will be associated with a wider gap between the investment and disinvestment thresholds. This comparative static result extends straightforwardly to the context of a plant with multiple capital inputs discussed above. However to identify the effects of uncertainty on investment empirically we will typically rely on measures of uncertainty that vary over time for the same firm. Policy interest also centres on the effects of changes in the level of uncertainty. It would therefore be useful to obtain a theoretical characterisation of the effect on a firm's investment policy of a change in the level of uncertainty that it faces. We develop a new result, Proposition 1 below, which takes a step in this direction by analysing the case of a temporary change in the level of uncertainty. In particular, we consider the effects of a change in the distribution of demand shocks in the current period, holding constant the distribution of demand shocks in all future periods.

For the multiple lines of capital model outlined above in section (2.2), Proposition 1 demonstrates that such a temporary increase in uncertainty leads to a similarly temporary increase in the gap between the investment and disinvestment thresholds. To do this we use a broader concept of uncertainty, second order stochastic dominance, which can be defined by: "If the distribution $F_{A}(P)$ stochastically dominates $F_{B}(P)$ then for any outcome $P_{A}$ from the dominating distribution the outcome from the dominated distribution is equal to that plus a mean preserving spread, so that $P_{B}=P_{A}+\varepsilon$, where the random variable $\varepsilon$ has mean zero and positive variance". For the standard class of Brownian motion 
models the definitions of second order dominance and variance are equivalent, while for more general distributions second order dominance always implies lower variance whilst the converse is often true although there can be exceptions ${ }^{11}$.

Proposition 1: An increase in demand uncertainty, defined in terms of second order stochastic dominance, in the current period, holding constant demand uncertainty in all future periods, will weakly increase the gap between the disinvestment and investment thresholds for all lines of capital in the current period.

Proof: See Appendix A.

This is the caution effect whereby increases in uncertainty increase the probability of making expensive mistakes and lead the plant to pursue a more cautious investment policy.

\subsection{Firm-Level Investment Behaviour}

Investment at the firm level will be the aggregate of investment in individual lines of capital within each plant. Hence firm-level investment will depend on the distribution of all lines of capital between their investment thresholds. To analyse this further we first consider the firm's positive investment expenditures. First, we define $F(x)$ to be the cumulative density of capital within each firm ${ }^{12}$ that would respond to a positive demand shock of size $x \geq 0$. This implies, for example, that $F(0)=0$ because all lines of capital will be either on or below their investment demand threshold and so will not respond to a size zero demand shock. In contrast, $F(\overline{\Delta p})=1$, for example, would imply that all lines of capital

\footnotetext{
${ }^{11}$ For further results and details of stochastic dominance, see Rothschild and Stiglitz (1970).

${ }^{12}$ This can equivalently be defined at the proportion of all capital within each firm which would respond to a positive demand shock of size $x$.
} 
(and hence all capital) would start investing after a (presumably large) demand shock of size $\overline{\Delta p}$.

Second, we can define, $d \log \kappa(x, \Delta p)=\iota(x, \Delta p)$, the positive investment function for lines of capital at each point $x$ of this cumulative density $F(x)$ in response to a positive demand shock of size $\Delta p \geq 0$, as follows ${ }^{13}$

$$
\begin{aligned}
& \iota(x, \Delta p)>0 \text { if } \quad \Delta p>x \\
& \iota(x, \Delta p)=0 \text { if } \quad \Delta p \leq x
\end{aligned}
$$

That is, $\iota(x, \Delta p)$ is the change in the log of the capital stock for the lines of capital that would just start to invest in response to a shock of size $x$, if they actually face a shock of size $\Delta p$. The right hand side conditions follow from the definition of $x$ as the smallest demand shock required to move capital at that position up to the investment threshold. This investment function will be increasing in the size of the demand shock so that $\frac{\partial \iota(x, \Delta p)}{\partial \Delta p} \geq 0$. For firms with multiple lines of capital this investment function will also be convex (increasing at an increasing rate) due to the assumed supermodularity of capital in production, so that $\frac{\partial^{2} \iota(x, \Delta p)}{(\partial \Delta p)^{2}} \geq 0$. Combining these two definitions, and using the approximation that $d \log K=$ $\frac{I}{K}$ where $I$ is total firm investment and $K$ is the total capital stock, we can characterize the firm's investment rate given a demand shock of size $\Delta p$ as $^{14}$

$$
\frac{I}{K}=\int_{0}^{\Delta p} \iota(x, \Delta p) d F(x)
$$

\footnotetext{
${ }^{13}$ This investment function also depends on the whole distribution of capital $F($.$) . So it could$ be written out fully for a position $x$ and shock $\Delta p$ as $\iota(x, \Delta p, F()$.$) . However, since this reliance$ on the whole distribution $F($.$) does not affect the discussion of our main results, we use the$ abbreviated form $\iota(x, \Delta p)$ to simplify our notation.

${ }^{14}$ This can be justified by defining the firm level investment rate $\frac{I}{K}$ to be the capital weighted average (using $F(x)$ ) of the investment rate of each individual line of capital.
} 
Without imposing additional restrictions on the production function and the stochastic demand and productivity processes this investment function has no closed form analytic solution. But for the general class of investment problems defined by conditions (1) to (3) in section (2.2) we can derive predictions about firm-level investment dynamics from a second order Taylor expansion of investment around uncertainty and the demand shock.

\subsubsection{Short Run Dynamics}

We first consider the short run response of firm-level investment to demand shocks and changes in the level of uncertainty. In particular we can characterise the sign of these responses. To derive these empirical implications we take a Taylor expansion of investment defined in (2.1) in terms of firm-level demand shocks and uncertainty.

The first derivative of positive investment with respect to a demand shock is positive reflecting the impact on lines of capital already at the investment margin

$$
\begin{aligned}
\partial \frac{I}{K} / \partial \Delta p & =\int_{0}^{\Delta p} \frac{\partial \iota(x, \Delta p)}{\partial \Delta p} d F(x) \\
& \geq 0
\end{aligned}
$$

The second derivative of positive investment with respect to a demand shock is also positive,

$$
\begin{aligned}
\partial^{2} \frac{I}{K} /(\partial \Delta p)^{2} & =\int_{0}^{\Delta p} \frac{\partial^{2} \iota(x, \Delta p)}{(\partial \Delta p)^{2}} d F(x)+\left.\frac{\partial \iota(x, \Delta p)}{\partial \Delta p}\right|_{x=\Delta p} d F(\Delta p) \\
& \geq 0
\end{aligned}
$$

because the first term is non-negative by the assumed supermodularity of different lines of capital in production and the second term is non-negative by the non- 
decreasing nature of cumulative distribution functions. Thus the firm's investment rate is an increasing and convex function of the demand shock.

The first derivative of positive investment with respect to a temporary increase in uncertainty will be negative. This is because, as Proposition 1 notes, higher uncertainty increases the real option value associated with investment and raises the investment threshold. So with higher uncertainty the new investment function, $\iota^{\prime}(x, \Delta p)$, defined according to the old distribution of capital $F(x)$, will be less than the old investment function, so that $\iota^{\prime}(x, \Delta p) \leq \iota(x, \Delta p)$. Hence we can write,

$$
\begin{aligned}
\partial \frac{I}{K} / \partial \sigma & =\lim _{d \sigma \rightarrow 0} \int_{0}^{\Delta p} \frac{\iota^{\prime}(x, \Delta p)-\iota(x, \Delta p)}{d \sigma} d F(x) \\
& \leq 0
\end{aligned}
$$

where the second line follows because limits preserve weak inequalities ${ }^{15}$.

Finally, considering the cross product term in the Taylor expansion we see that the cross effect of a positive demand shock and a temporary increase in uncertainty on positive investment is negative. This is because higher levels of uncertainty raise the investment threshold leading to less lines of capital investing. This reduces the investment response for all lines of capital that are investing due to the supermodularity of capital in production, so that $\partial \iota^{\prime}(x, \Delta p) / \partial \Delta p \leq$ $\partial \iota(x, \Delta p) / \partial \Delta p$. Combining this relationship and (2.4) we can state that

$$
\begin{aligned}
\partial^{2} \frac{I}{K} / \partial \sigma \partial \Delta p & =\lim _{d \sigma \rightarrow 0} \int_{0}^{\Delta p} \frac{\partial \iota^{\prime}(x, \Delta p) / \partial \Delta p-\partial \iota(x, \Delta p) / \partial \Delta p}{d \sigma} d F(x) \\
& \leq 0
\end{aligned}
$$

\footnotetext{
${ }^{15}$ Proposition 1 refers to the increase in the gap between the investment and disinvestment thresholds in terms of a stochastic dominance relationship between two distributions, rather than in terms of a continuous function of uncertainty. So this derivative should be interpreted as a Radon-Nikodym functional derivative on the probability space of demand distributions, rather than the usual calculus concept. However, to avoid unnecessary notation and complexity, and because this does not affect the empirical interpretation of this derivative, we will not elaborate any further on this point but refer the interested reader instead to Bartle (1966).
} 
where the second line again follows by the preservation of weak inequalities in the limit.

Thus far we have only considered the effects on positive investment expenditures. Deriving the corresponding results from the equivalent expansion for disinvestment uses a similar approach and a summary of both sets of results is presented in Table 4 below.

Table 4: The Short Run Sign of Demand Shocks $(\Delta p)$ and Uncertainty $(\sigma)$ on Investment

\begin{tabular}{|l|c|c|c|c|}
\hline Taylor Expansion Terms & $\Delta p$ & $\Delta p^{2}$ & $\sigma \Delta p$ & $\sigma$ \\
\hline & $\partial \frac{I}{K} / \partial \Delta p$ & $\partial^{2} \frac{I}{K} / \partial \Delta p^{2}$ & $\partial^{2} \frac{I}{K} / \partial \sigma \partial \Delta p$ & $\partial \frac{I}{K} / \partial \sigma$ \\
\hline Positive Investment & + & + & - & - \\
\hline Disinvestment & + & - & - & + \\
\hline
\end{tabular}

As we saw in Table $2 \mathrm{~b}$, almost all observations on total firm-level investment in our data cover firms that are simultaneously investing and disinvesting. The total investment series we model measures gross investment expenditures net of sales of capital goods. Thus only the direct demand shock term and the uncertaintydemand shock interaction term have an unambiguous prediction on measured investment dynamics. A positive demand shock should result in more investment (or less disinvestment), and a higher level of uncertainty should reduce the response of investment (or disinvestment) to a given demand shock. For this reason we focus on testing these predictions in our empirical investigation. In principle, the short run signs of accelerating demand and the level of uncertainty on measured investment dynamics are ambiguous. However, because of the effects of positive sales growth and capital depreciation, the vast majority of the total 
investment observations are positive in our firm-level data set (about 96\% of observations). We would thus expect the short run effects of accelerating demand and higher uncertainty to be positive and negative respectively, consistent with the predictions for firms engaging in positive investment.

\subsubsection{Long Run Effects}

To investigate these predictions about the short run investment dynamics empirically, we need to control for longer run influences on the firm's capital stock. To do this we exploit the results of Bloom (2000a) which demonstrate that the long run growth rates of the firm's actual capital stock, $K_{t}$, and its hypothetical level under costless reversibility, $K_{t}^{*}$, will be equal, so that their levels will be cointegrated. Thus, the long run behaviour of the actual capital stock under partial irreversibility can be modelled using its much simpler hypothetical value under complete reversibility plus a stationary deviation

$$
\log K_{t}=\log K_{t}^{*}+e_{t}
$$

where $e_{t}$ is a stationary, autocorrelated error term bounded by the distance between the disinvestment and investment thresholds.

Notice that this does not imply that the actual capital stock and its hypothetical reversible level will be equal on average - there is no requirement for the deviation $e_{t}$ to be mean zero. Similarly this result does not rule out any particular long run relationship between uncertainty and the level of the capital stock. As has been stressed by Abel and Eberly (1995) and Caballero (1999), among others, the impact of higher uncertainty on the average capital stock level in the long run is theoretically ambiguous in models with partial irreversibility, since higher 
uncertainty retards downward as well as upward adjustments. For this reason we allow for the possibility of long run effects of uncertainty on the level of the capital stock, as well as the predicted effects on short run investment dynamics, in our empirical specification.

\section{Empirical Specification}

Since the distribution of projects between their disinvestment and investment thresholds is dependent on the past history of demand shocks, the empirical dynamics of investment will be rich and persistent. A convenient starting point for our empirical specification is an error correction model, which separates parameters describing the short run investment dynamics from those describing the long run evolution of the capital stock ${ }^{16}$. Linear error correction models have been used in the aggregate investment literature by, for example, Bean (1981), and in the micro investment literature by Bond et al (1999).

The basic error correction model has the form

$\frac{I_{t}}{K_{t-1}} \approx \Delta \log K_{t}=\alpha_{0}+\alpha_{1}(L) \Delta \log K_{t-1}+\alpha_{2}(L) \Delta \log K_{t}^{*}+\alpha_{3}\left(\log K_{t-s}^{*}-\log K_{t-s}\right)+v_{t}$

where $\alpha_{1}(L)$ and $\alpha_{2}(L)$ are polynomials in the lag operator $(L)$. This is consistent, for example, with an ARMA approximation to the stationary error term in (2.6). Since the consistency of the Generalised Method of Moments (GMM) estimator

\footnotetext{
${ }^{16}$ It should be noted that a $\mathrm{Q}$ investment model, by assuming perfect competition and constant returns, assumes away any role for real options from the outset. Hence, while Abel and Eberly's (1994) generalisation of the Q model can be used to test for the presence of non-convex adjustment costs, because it assumes perfect competition and constant returns to scale, it rules out any real options effects by construction. In a similar manner the standard investment Euler equation, which does not permit the type of kinked adjustment costs that arises from partial irreversibility, also assumes away any role for real options from the outset.
} 
we use depends on orthogonality between the residual error term $\left(v_{t}\right)$ and a set of suitably lagged instruments, our empirical dynamic specification is selected with this criterion in mind.

Our specification for firm i's hypothetical capital stock under complete reversibility has the simple log-linear form

$$
\log K_{i t}^{*}=\log Y_{i t}+\gamma_{1} \sigma_{i t}+\gamma_{2}\left(\frac{C_{i t}}{K_{i, t-1}}\right)+A_{i}+B_{t}
$$

where $Y_{i t}$ is firm i's sales in period t, $\sigma_{i t}$ is a measure of uncertainty, $\left(\frac{C_{i t}}{K_{i, t-1}}\right)$ is cash flow scaled by the previous period's capital stock, $A_{i}$ is an (unobserved) firm-specific effect and $B_{t}$ is a time-specific effect, common to all firms.

For the baseline case in which $\gamma_{1}=\gamma_{2}=0$, Proposition 2 below shows that this expression for the desired capital stock is consistent with our general model with multiple capital goods.

Proposition 2: The log of the capital stock under complete reversibility is equal to the $\log$ of sales plus a bounded term $Z_{i t}$, so that we can write

$$
\log K_{i t}^{*}=\log Y_{i t}+Z_{i t}
$$

\section{Proof: See Appendix A}

Allowing for time effects in (3.2) controls for variation in costs of capital to the extent that these are common to all firms. Firm effects allow for variation across firms in the elasticity of demand, and for some firm variation in relative prices. The uncertainty term allows for a possible long-run effect of uncertainty on the firm's capital-sales ratio. The cash flow term allows for possible effects from 
liquidity constraints (cf. Fazzari, Hubbard and Petersen (1988)) or managers over-investing free cash flow (cf. Jensen (1986)). Whilst this is not our main interest in this analysis, many previous studies have found cash flow terms to be significant in reduced form investment equations. We therefore follow Guiso and Parigi (1999) in including such terms so as not to mistake uncertainty effects for omitted cash flow effects. We also found that the inclusion of cash flow terms was important for the validity of the orthogonality conditions we use in estimation.

Combining equations (3.1) and (3.2) gives a linear error correction model relating the current investment rate to lagged investment rates, current and lagged changes in sales, uncertainty and cash flow, and a lagged error correction term. We include additional interaction terms between uncertainty and sales growth, and powers of sales growth, in order to test for the heterogeneous and non-linear investment dynamics predicted by our theoretical model. Starting from a more general specification, exclusion of insignificant terms led to our basic model

$$
\begin{aligned}
\frac{I_{i t}}{K_{i, t-1}}= & \beta_{1} \Delta y_{i t}+\beta_{2}\left(\Delta y_{i t}\right)^{2}+\beta_{3}\left(\sigma_{i t} \Delta y_{i t}\right)+\beta_{4} \Delta \sigma_{i t}+\beta_{5} \Delta \frac{C_{i t}}{K_{i, t-1}} \\
& +\beta_{6}(y-k)_{i, t-1}+\beta_{7} \sigma_{i, t-1}+\beta_{8} \frac{C_{i t-1}}{K_{i, t-2}}+b_{t}+a_{i}+u_{i t}
\end{aligned}
$$

where $k_{i t}=\log K_{i t}$ and $y_{i t}=\log Y_{i t}$. The first four terms correspond to the influences on short run investment dynamics analysed in section (2.4.1). Our theoretical analysis predicts that $\beta_{1}>0$ and $\beta_{3}<0$, whilst it is likely that $\beta_{2}>0$ and $\beta_{4}<0$ given that our sample is dominated by firms with positive investment. We require $\beta_{6}>0$ for the estimated model to be consistent with 'error correcting' behaviour (i.e. a capital stock below its desired level to be followed eventually by upward adjustment), whilst the long run effect of uncertainty on the level of the capital-sales ratio $\left(\beta_{7}\right)$ is theoretically ambiguous. 
Whilst the inclusion of squared sales growth and the uncertainty interaction term in this model tests the null hypothesis of a common, linear error correction specification against the non-linear and heterogeneous investment dynamics predicted by our theoretical analysis, it is nevertheless likely that the actual investment dynamics under the alternative would be more heterogeneous across both firms and time than this common parameters specification permits. Unfortunately, it is not possible to allow for arbitrary heterogeneity in slope coefficients in models with predetermined and endogenous covariates. At one level we can consider the included dynamics in (3.4) to be removing a common component of the deviation term $\left(e_{i t}\right)$ from the long run specification (2.6). Provided the residual component $\left(u_{i t}\right)$ is orthogonal to our instruments, this would in principle allow us to identify common long run parameters of the specification for $\log K_{i t}^{*}$. However it should be noted that the status of the estimated short run dynamics under the alternative is less clear.

To confirm that our empirical test does have power to detect the short run dynamics implied by our theoretical model, Appendix C reports the results of applying this test using simulated data generated by a partial irreversibility model of the type analysed in section 2 . These simulations indicate that the short run dynamics predicted in section (2.4) would be detected by this empirical analysis if the data were indeed generated by a model of this type. In particular, estimating a non-linear error correction model on the generated data, we find that the coefficient on the squared sales growth term $\left(\Delta y_{i t}\right)^{2}$ is significantly positive, and the coefficient on an uncertainty interaction term $\left(\sigma_{i} \Delta y_{i t}\right)$ is significantly negative. Moreover, the inclusion of a linear error correction term $(y-k)_{i, t-1}$ appears to be 
sufficient to control for the serial correlation found in static specifications, so that the estimated equation does not fail the serial correlation test or Sargan-Hansen test of overidentifying restrictions in samples of this size.

Estimation uses the system GMM estimator for dynamic panel data (see Blundell and Bond, 1998) which extends the standard moment conditions in the firstdifferenced GMM estimator subject to additional (testable) initial condition restrictions. The system estimator combines equations in first-differences, from which the firm-specific effects are eliminated by the transformation; and equations in levels, for which the instruments used must be orthogonal to the unobserved firm-specific effects. The overidentifying restrictions are tested using a SarganHansen statistic, and residual serial correlation tests are reported. A goodness of fit measure for our models is also provided, which is the squared correlation between the predicted level of the investment rate and the actual investment rate. This squared correlation between the actual and predicted variables is equivalent to the standard $\mathrm{R}^{2}$ for OLS regressions and has been suggested as a goodness of fit measure for IV regressions (see for example Windmeijer (1995)).

\section{Data}

\subsection{The Measurement of Uncertainty}

Although the model developed above discusses the response of investment to demand and productivity shocks, the notion of uncertainty we have in mind is much broader in scope. In reality firms will be uncertain about future prices, wages rates, exchange rates, technologies, consumer tastes and government policies. In an attempt to capture all factors in one scalar proxy for firm-level uncertainty, we follow Leahy and Whited (1998) in using the standard deviation of the firm's 
daily stock returns, adjusted for gearing, denoted $\sigma_{i t}$. This measure includes on a daily returns basis the capital gain on the stock, dividend payments, rights issues, and stock dilutions. Such a returns measure provides a forward looking proxy for the volatility of the firm's environment which is implicitly weighted in accordance with the impact of these variables on profits $^{17}$.

A stock returns-based measure of uncertainty is also advantageous because the data is accurately reported at a sufficiently high frequency to use an annual measure. When using homoskedastic diffusion processes the variance of the sample variance is inversely related to the sampling frequency. Our sampling frequency of about 265 recordings a year therefore suggests low sample variance ${ }^{18}$. A disadvantage of using this measure is that the variability in stock market returns may not truly reflect fundamentals. Guiso and Parigi (1999), for example, use the variance implied by mangers' expected distributions of future variables, which they construct from a special survey. The results which we find below are qualitatively similar to theirs, even though we use different measures of uncertainty and, unlike them, we have panel data rather than a single cross section.

In the time series dimension (see Figure 1) there is a spike in uncertainty in 1975 around the time of the first OPEC oil shock. There is as another peak in 1988 when annual measures are affected by the October 1987 stock market crash. In common with Davis and Haltiwanger (1992) we also find that these

\footnotetext{
${ }^{17}$ To allow for possible effects of market-wide bubbles and fads we also calculated a second measure of uncertainty, using the standard deviation of the firm's daily share returns normalized by the return on the FTSE All-Share index. Results using this normalized measure were very similar to those reported below, and are available on request from the authors. We also obtained qualitatively similar results whether we used the standard deviation or the variance as our measure of uncertainty

${ }^{18}$ For example, Andersen and Bollerslev (1998) use high frequency exchange rate data with 288 recordings per period and calculate that the implied measurement errors are less than $2.5 \%$ of the true volatility.
} 
macro sources of uncertainty are less important than firm-specific idiosyncratic shocks. For example, in our data only $17 \%$ of the variance of our uncertainty measure is accounted for by macro shocks. Of the residual about half is permanent idiosyncratic differences between firms and half is transitory idiosyncratic shocks.

\section{[FIGURE 1 ABOUT HERE]}

\subsection{Investment and Other Accounting Data}

The company data is taken from Datastream and consists of 672 manufacturing companies quoted on the UK stock market from 1972 to 1991. Investment in fixed capital assets is measured net of revenue from asset sales, which may nevertheless under record the value of disinvestment. Our capital stock measure is derived from the book value of the firm's stock of net fixed assets, using the investment data in a standard perpetual inventory formula. Real sales are deflated using the aggregate GDP deflator. Cash flow is reported post-tax earnings plus depreciation deductions. Appendix B provides further details and Table 5 reports some summary statistics for the sample.

Table 5: Descriptive Statistics of 672 firms, 6019 observations

\begin{tabular}{|l|l|l|l|l|l|l|l|}
\hline & mean & median & \multicolumn{2}{|l|}{ standard deviation } & min. & max. \\
\hline & & & total & within & betwn & & \\
\hline$\left(I_{t} / K_{t-1}\right)$ (investment rate) & 0.128 & 0.093 & 0.13 & 0.11 & 0.10 & -0.11 & 1.21 \\
\hline$\Delta y_{t}(\log$ real sales growth) & 0.031 & 0.026 & 0.16 & 0.14 & 0.09 & -0.79 & 1.22 \\
\hline$\sigma_{t}$ (s.d. of share returns) & 1.56 & 1.41 & 0.68 & 0.53 & 0.47 & 0.01 & 5.00 \\
\hline$\left(C_{t} / K_{t-1}\right)$ (cash flow term) & 0.18 & 0.140 & 0.16 & 0.09 & 0.17 & -0.09 & 1.96 \\
\hline Employment & 8,400 & 1,481 & 24,492 & 8,461 & 19,450 & 26 & 21,200 \\
\hline Observations per firm & 11.3 & 11 & 4.7 & 0 & 4.7 & 3 & 20 \\
\hline
\end{tabular}


As a preliminary step we present some basic descriptive regressions in Table 6 . There is a strong negative correlation between investment rates and our measure of uncertainty which is illustrated in column (1). Column (2) then includes the growth of sales and its interaction with uncertainty. It is the latter variable which is key for our theoretical results. There is a standard accelerator effect of sales but, more importantly, the coefficient on sales growth is significantly lower for firms with more volatile share returns. In the final column we condition on cash flow as an additional regressor, which is highly significant. The interaction of sales growth with uncertainty remains negative and significant. The linear effect of uncertainty now reverses sign and is insignificant at conventional levels. Although these results do not control for endogeneity and firm-specific effects, it is interesting that our key theoretical prediction is consistent with the raw data.

Table 6: Descriptive Investment Regressions

\begin{tabular}{|l|l|l|l|}
\hline$\left(I_{t} / K_{t-1}\right)$ & $(1)$ & $(2)$ & $(3)$ \\
\hline Uncertainty $\left(\sigma_{t}\right)$ & -0.015 & -0.005 & 0.003 \\
\hline & $(0.003)$ & $(0.002)$ & $(0.002)$ \\
\hline Sales Growth $\left(\Delta y_{t}\right)$ & & 0.453 & 0.338 \\
\hline & & $(0.025)$ & $(0.023)$ \\
\hline Uncert. $\times$ Sales Growth $\left(\sigma_{t} * \Delta y_{t}\right)$ & & -0.033 & -0.035 \\
\hline & & $(0.013)$ & $(0.012)$ \\
\hline Cash Flow $\left(C_{t} / K_{t-1}\right)$ & & & 0.381 \\
\hline & & & $(0.011)$ \\
\hline
\end{tabular}

NOTES:- Estimation by OLS levels, 6019 observations. 


\section{Econometric Results}

Table 7 contains our main econometric results estimated by $\mathrm{GMM}^{19}$. The first column contains a basic linear error correction model augmented to include cash flow variables. The error correction term is correctly signed and of a similar magnitude to others in the literature (e.g. Bond, Harhoff and Van Reenen, 1999). Current sales growth and both the level and the change in the cash flow variable are also significant determinants of investment. The second column adds in a non-linear term in squared sales growth which is positive and highly significant, consistent with our theoretical prediction, and noticeably improves the fit of the model. The third column includes our uncertainty variables - the change in uncertainty, the lagged level of uncertainty, and the interaction between uncertainty and sales growth. The level of uncertainty is negative but insignificant, which is consistent with the ambiguous effect of uncertainty on the level of the capital stock in the long run, discussed in section (2.4.2). The change in uncertainty is negative and weakly significant at the $10 \%$ level, which is consistent with the predicted short run effect of higher uncertainty on investment for positive investment firms. More importantly the interaction term is negative and significant at the $5 \%$ level, which is again consistent with the prediction of our analysis in section (2.4.1). In Column (4) we drop the level uncertainty term and find that while the interaction term remains strongly significant, the change in uncertainty becomes insignificant. Column (5) reports our final preferred specification which includes our key term, the interaction between uncertainty and sales growth ${ }^{20}$. This vari-

\footnotetext{
${ }^{19}$ The instrument set used is detailed in the Notes to the Table. Our main results are highly robust to a range of alternative instrument sets

${ }^{20} \mathrm{~A}$ joint test on the exclusion of the level and change in uncertianty terms from the specification in column $(3)$ does not reject this restriction $(\mathrm{p}$-value $=0.17)$.
} 
able is negative and significant at the $5 \%$ level, consistent with our prediction that uncertainty reduces the firm's responsiveness to demand shocks.

Table 8 probes the results further to investigate where we are achieving identification of the uncertainty interaction term. We decompose the uncertainty measure into three components - a common macroeconomic factor $\left(\bar{\sigma}_{t}\right)$, a timeinvariant firm specific factor $\left(\bar{\sigma}_{i}\right)$ and a within-firm within-year residual component $\left(\widetilde{\sigma}_{i t}=\sigma_{i t}-\bar{\sigma}_{i}-\bar{\sigma}_{t}\right)$. Interestingly, it is the interactions with the firm specific components (especially $\widetilde{\sigma}_{i t}$ ) which are most informative. The aggregate uncertainty interaction is the least informative, being perversely signed in the first column and always insignificantly different from zero. This may explain why it has proved hard to identify significant effects of uncertainty using macroeconomic data. It is only by exploiting the micro data that we observe sufficient variation in our measure of uncertainty to be able to identify the effect of uncertainty in retarding the firm's responsiveness to shocks. 
Table 7: Uncertainty and Investment

\begin{tabular}{|l|c|c|c|c|c|}
\hline Dependent Variable $\left(I_{t} / K_{t-1}\right)$ & $\mathbf{( 1 )}$ & $\mathbf{( 2 )}$ & $\mathbf{( 3 )}$ & $\mathbf{( 4 )}$ & $\mathbf{( 5 )}$ \\
\hline Sales Growth $\left(\Delta y_{t}\right)$ & 0.255 & 0.151 & 0.382 & 0.400 & 0.413 \\
\hline & $(0.018)$ & $(0.059)$ & $(0.136)$ & $(0.139)$ & $(0.139)$ \\
\hline Change in Cash Flow $\left(\Delta C_{t} / K_{t-1}\right)$ & 0.160 & 0.263 & 0.260 & 0.255 & 0.272 \\
\hline & $(0.038)$ & $(0.132)$ & $(0.124)$ & $(0.126)$ & $(0.125)$ \\
\hline Lagged Cash Flow $\left(C_{t-1} / K_{t-2}\right)$ & 0.482 & 0.532 & 0.533 & 0.543 & 0.544 \\
\hline & $(0.029)$ & $(0.109)$ & $(0.103)$ & $(0.103)$ & $(0.102)$ \\
\hline Error Correction Term $(y-k)_{t-1}$ & 0.049 & 0.056 & 0.054 & 0.054 & 0.053 \\
\hline & $(0.010)$ & $(0.029)$ & $(0.026)$ & $(0.026)$ & $(0.026)$ \\
\hline Sales Growth Sqrd. $\left(\Delta y_{t} * \Delta y_{t}\right)$ & & 0.481 & 0.512 & 0.494 & 0.500 \\
\hline & & $(0.175)$ & $(0.152)$ & $(0.150)$ & $(0.151)$ \\
\hline Change in Uncertainty $\left(\Delta \sigma_{t}\right)$ & & & -0.023 & -0.012 & \\
\hline & & & $(0.012)$ & $(0.008)$ & \\
\hline Lagged Uncertainty $\left(\sigma_{t-1}\right)$ & & & -0.015 & & \\
\hline & & & $(0.011)$ & & \\
\hline Uncert. $\times$ Sales Growth $\left(\sigma_{t} * \Delta y_{t}\right)$ & & & -0.162 & -0.165 & -0.167 \\
\hline & & & $(0.067)$ & $(0.068)$ & $(0.068)$ \\
\hline \hline Goodness of Fit - Corr. $(I / K, I / K)^{2}$ & 0.259 & 0.287 & 0.285 & 0285 & 0.307 \\
\hline 2nd order serial correlation $(\mathrm{p})$ & 0.048 & 0.102 & 0.069 & 0.078 & 0.091 \\
\hline Sargan $(\mathrm{p})$ & 0.510 & 0.709 & 0.699 & 0.629 & 0.560 \\
\hline
\end{tabular}

NOTES:- The total number of observations (for all columns) is 5347, on a sample period of 1973 to 1991, with 672 firms. A full set of time dummies is included in every specification. Estimation uses a GMM System estimator (see Blundell and Bond, 1998) calculated with DPD98 for Gauss (see Arellano and Bond, 1998). We report one step coefficient estimates with heteroskedasticity-consistent standard errors. The instruments used for columns (3) to (5) in the first-differenced equations are lags two and three of the variables: $\left(\frac{I}{K}\right)_{t-2}$ and $\left(\frac{I}{K}\right)_{t-3}, \Delta y_{t-2}$ and $\Delta y_{t-3},(y-k)_{t-2}$ and $(y-$ $k)_{t-3},\left(\frac{C_{t-2}}{K_{t-3}}\right)$ and $\left(\frac{C_{t-3}}{K_{t-4}}\right)$, and $\sigma_{t-2}, \sigma_{t-3}$ and $\sigma_{t-4}$; the instruments used in the levels equations are $\Delta\left(\frac{I}{K}\right)_{t-1}, \Delta \Delta y_{t-1}, \Delta\left(\frac{C_{t-1}}{K_{t-2}}\right), \Delta \Delta(y-k)_{t-1}$ and $\Delta \sigma_{t-1}$. Columns (1) and (2) use this instrument set but with the uncertainty variables excluded. Instrument validity is tested using a Sargan-Hansen test of the overidentifying restrictions for the two step GMM estimator. The test for no second order serial correlation in the firstdifferenced residuals is also reported. 
Table 8: Separating Time, Firm and Residual Variation in

Uncertainty
\begin{tabular}{|l|c|c|c|c|}
\hline Dependent Variable $\left(I_{t} / K_{t-1}\right)$ & $\mathbf{( 1 )}$ & $\mathbf{( 2 )}$ & $\mathbf{( 3 )}$ & $\mathbf{( 4 )}$ \\
\hline Sales Growth $\left(\Delta y_{t}\right)$ & 0.127 & 0.141 & 0.474 & 0.499 \\
\hline & $(0.052)$ & $(0.053)$ & $(0.182)$ & $(0.184)$ \\
\hline Change in Cash Flow $\left(\Delta C_{t} / K_{t-1}\right)$ & 0.270 & 0.263 & 0.287 & 0.280 \\
\hline & $(0.124)$ & $(0.127)$ & $(0.122)$ & $(0.124)$ \\
\hline Lagged Cash Flow $\left(C_{t-1} / K_{t-2}\right)$ & 0.531 & 0.533 & 0.551 & 0.553 \\
\hline & $(0.101)$ & $(0.103)$ & $(0.100)$ & $(0.101)$ \\
\hline Error Correction Term $(y-k)_{t-1}$ & 0.054 & 0.056 & 0.047 & 0.049 \\
\hline & $(0.027)$ & $(0.027)$ & $(0.026)$ & $(0.026)$ \\
\hline Sales Growth Squared $\left(\Delta y_{t} * \Delta y_{t}\right)$ & 0.497 & 0.507 & 0.534 & 0.537 \\
\hline & $(0.170)$ & $(0.157)$ & $(0.148)$ & $(0.162)$ \\
\hline Time Uncert. $\times$ Sales Growth $\left(\bar{\sigma}_{t}\right) *\left(\Delta y_{t}\right)$ & 0.016 & & & -0.051 \\
\hline & $(0.150)$ & & & $(0.135)$ \\
\hline Firm Uncert. $\times$ Sales Growth $\left(\bar{\sigma}_{i}\right) *\left(\Delta y_{t}\right)$ & & -0.130 & & -0.136 \\
\hline & & $(0.105)$ & & $(0.107)$ \\
\hline Resid. Uncert. $\times$ Sales Growth $\left(\sigma_{i t}-\bar{\sigma}_{i}-\bar{\sigma}_{t}\right) *\left(\Delta y_{t}\right)$ & & & -0.225 & -0.230 \\
\hline & & & $(0.102)$ & $(0.103)$ \\
\hline \hline Goodness of Fit - Corr. $(I / K, I / K)^{2}$ & 0.307 & 0.298 & 0.311 & 0.288 \\
\hline 2nd order serial correlation $(\mathrm{p})$ & 0.096 & 0.094 & 0.132 & 0.106 \\
\hline Sargan $(\mathrm{p})$ & 0.399 & 0.490 & 0.383 & 0.452 \\
\hline
\end{tabular}

NOTES:- The total number of observations (for all columns) is 5347, on a sample period of 1973 to 1991, with 672 firms. A full set of time dummies is included in every specification. Estimation uses a GMM System estimator (see Blundell and Bond, 1998) calculated with DPD98 for Gauss (see Arellano and Bond, 1998). We report one step coefficient estimates with heteroskedasticity-consistent standard errors. The instruments used in the first-differenced equations are lags two and three of the variables: $\left(\frac{I}{K}\right)_{t-2}$ and $\left(\frac{I}{K}\right)_{t-3}, \Delta y_{t-2}$ and $\Delta y_{t-3},(y-k)_{t-2}$ and $(y-k)_{t-3},\left(\frac{C_{t-2}}{K_{t-3}}\right)$ and $\left(\frac{C_{t-3}}{K_{t-4}}\right)$, and $\sigma_{t-2}, \sigma_{t-3}$ and $\sigma_{t-4}$; the instruments used in the levels equations are $\Delta\left(\frac{I}{K}\right)_{t-1}$, $\Delta \Delta y_{t-1}, \Delta\left(\frac{C_{t-1}}{K_{t-2}}\right), \Delta \Delta(y-k)_{t-2}$ and $\Delta \sigma_{t-1}$. Instrument validity is tested using a Sargan-Hansen test of the overidentifying restrictions for the two step GMM estimator. The test for no second order serial correlation in the first-differenced residuals is also reported. 
We have conducted many robustness tests on these results, some of which we now report. First, cash flow has no strong theoretical justification for being included in these models. Unfortunately, omitting the cash flow terms resulted in evidence of empirical mis-specification. Dropping both cash flow terms from the specification in column (5) of Table 7 caused the Sargan test to reject the overidentifying restrictions $(\mathrm{p}$-value $=0.010)$ and produced significant second order serial correlation in the first-differenced residuals (p-value 0.049). Nevertheless, the interaction of uncertainty and sales growth was still found to be negative and significant in this specification, with a point estimate of -0.142 and a standard error of 0.065 .

Secondly, we experimented with a range of additional non-linear and interaction terms, none of which were found to be statistically significant in our sample ${ }^{21}$.

Thirdly, an implication of real options theory stressed by Guiso and Parigi (1999) is that the effect of uncertainty should be stronger for firms with more market power. We investigated whether the interaction term was stronger for firms in industries where market power is likely to be stronger (as proxied by concentration, trade barriers, etc.). We found no evidence that this was the case, although it could be that our industry-level proxies are not good measures of the firm's market power.

Finally, we constructed an alternative measure of uncertainty after normalising the firm's stock returns by the return on the FTSE All Share index for the same day. This measure gave somewhat more precise coefficient estimates than our basic results, presumably because some of the general stock market noise has been

\footnotetext{
${ }^{21}$ For example, we included interactions of uncertainty with squared sales growth, cash flow and the error correction term. The joint Wald test gave a $\chi^{2}(3)=4.42$ with a p-value of 0.219 .
} 
removed from the measure of uncertainty. For example, in the specification which corresponds to column (5) of Table 7, the coefficient on the uncertainty interaction term rises to -0.196 with a standard error of 0.074 . All these additional results are available from the authors on request.

\subsection{Evaluation of the Quantitative Impact of Uncertainty on Invest- ment Dynamics}

The results suggest an important role for uncertainty in retarding the responsiveness of investment to demand shocks. We conducted some simple simulations where we increased sales in the firm permanently by $2.5 \%, 5 \%$ and $10 \%$. We then tracked the path of investment and capital predicted by our preferred empirical specification as the firm responds to this shock. Our model suggests that firms with high uncertainty will respond more slowly to this shock than firms with low uncertainty. Consequently we examined the half life of the capital stock adjustment (how many years it takes the firm to get half-way towards its new long-run capital stock level) at different percentiles of the empirical uncertainty distribution (10th, 25th, 50th, 75th and 90th). Table 9 contains the results.

Table 9: Investment Half Lives in response to a $2.5 \%, 5 \%$ and $10 \%$

shock to demand, by uncertainty percentiles

\begin{tabular}{|l|l|l|l|l|l|}
\hline & $10^{\text {th }}(\sigma=0.84)$ & $25^{\text {th }}(\sigma=1.08)$ & $50^{\text {th }}(\sigma=1.41)$ & $75^{\text {th }}(\sigma=1.89)$ & $90^{\text {th }}(\sigma=2.46)$ \\
\hline $2.5 \%$ & 8 & 9 & 10 & 11 & 13 \\
\hline $5 \%$ & 8 & 9 & 10 & 11 & 12 \\
\hline $10 \%$ & 7 & 8 & 9 & 11 & 12 \\
\hline
\end{tabular}

The exact size of the shock makes relatively little difference to the results. For the smallest shock, moving from the 25th to the 75 th percentile of the uncertainty 
distribution increases the half life by two years. This is the order of magnitude by which our measure of aggregate uncertainty increased between 1973 and 1975, a very large change by historical standards. This is illustrated in more detail in Figures 2 and 3, which track the paths of investment and the capital stock over a ten year period in response to a $2.5 \%$ demand shock.

\section{[FIGURES $2 \& 3$ ABOUT HERE]}

The largest effects of different levels of uncertainty are manifest in the first year. So uncertainty is quantitatively important in retarding the investment response, but these effects are not large.

A second gauge of the importance of uncertainty and irreversibility is provided by comparing the gain in the goodness of fit of our preferred investment model in column (5) of Table 7, which includes the uncertainty interaction term and the squared sales growth term, in comparison to the more standard linear specification in column (1) of Table 7. To do this we calculate a year-by-year correlation between actual and predicted investment rates for both our preferred specification and the standard model. We take these two annual goodness of fit series and plot their annual difference in Figure 4 (left axis), as a time varying indicator of the improvement in fit from accounting for the effects of uncertainty and partial irreversibility on short run investment dynamics. In Figure 4 (right axis) we also plot the yearly average rate of change of sales growth as an indicator of the turning points in the business cycle. Turning points in the business cycle should be highlighted by rapid changes in the rate of sales growth as growth rates slow down going into recession or speed up heading into a boom. 


\section{[FIGURES 4 ABOUT HERE]}

It can be seen from Figure 4 that the improvement in fit tracks the positive turning points of the business cycles (correlation of 0.564 ), with large improvements evident in the late 1970s as the UK was recovering from the first oil shock, and again in the early 1980s when the UK was recovering from the monetarist experiment and the second oil shock. Interestingly this parallels the results of Caballero et al. (1995) and Cooper et al. (1999) who report that taking into account the non-linearities induced by fixed costs of investment leads to an improvement in investment fit most notably around turning points in the investment cycle $^{22}$. This suggests that accounting for the non-linearities induced by partial irreversibility will be most important in periods of large investment fluctuations.

\section{Conclusions}

In this paper we have presented a theoretical framework for analysing firm-level investment under uncertainty. We characterise the problem as one where a firm has multiple projects ('plants' or 'lines of capital'). Under fairly general conditions over the production function and the distribution of the demand shocks facing the firm we approximate the aggregate firm-level investment dynamics to a second order. We emphasise a neglected theoretical implication of real options theory. Firms facing increased uncertainty should be more cautious - they should exhibit a lower responsiveness of investment to demand shocks than firms subject to less

\footnotetext{
${ }^{22}$ The estimation approach of both papers differs from ours in that they estimate investment models at the plant level and track the cross sectional distribution of plant level investment to model aggregate investment.
} 
uncertainty. This approach also predicts a non-linear response of firm investment to demand shocks.

We test these predictions using a panel of 672 UK manufacturing firms between 1973 and 1991. Using a measure of uncertainty based on the daily stock market returns of our firms, we estimate non-linear error correction models of investment. The key implication of the theory is supported by the data, with a significantly lower response of investment to sales growth when uncertainty is high. This is robust to a number of experiments and primarily related to the firm-specific components of uncertainty rather than to general macroeconomic uncertainty. This may explain why it is difficult to detect these important effects in the macro data. We also find significant non-linearity in the investment dynamics, with a convex relationship between investment rates and sales growth, as predicted by our theoretical analysis. As a secondary result, we find no significant evidence of any effect of our uncertainty measures on the level of the capital stock in the long run. This finding is also quite consistent with our theoretical framework.

This work is of course only a first step. The implications for short run investment dynamics also apply to more broadly defined investment goods, such as $\mathrm{R} \& \mathrm{D}$ and the development of information technology, which are clearly subject to considerable irreversibilities and uncertainty. More broadly, the hiring and training of labour could also be regarded as an investment process and would naturally be included as another type of 'capital' good in our general class of production functions. Investigating the importance of uncertainty for employment adjustment and the interrelationship between threshold behaviour for different inputs should be high on the agenda of future research. 


\section{Appendix A}

\section{Proof of Proposition 1}

Consider a firm which is thinking about undertaking a marginal investment. One way of formulating its decision is in terms of its choice over investing a unit of capital today versus waiting until next period. Let the firm's one period marginal revenue of capital be denoted by $R_{K}(K, P) \Delta t$ where $\Delta t$ is the length of the period, $K$ is the current capital stock, $P$ is the current level of market demand, and $B$ is the price of a unit of capital. Let the firm's value function be denoted $V(K, P)$, and its one period discount rate be denoted $\gamma=\exp (-r \Delta t)$. We examine the impact of a change in the distribution of demand shocks in the current period on its investment thresholds in the current period ${ }^{23}$. Since all future demand distributions are held constant the functional form of next period's continuation value function will be unaffected. This allows us to use the Bellman equation to examine the impact of temporary changes in demand distributions on the current investment thresholds while holding the future investment policy constant.

If the firm's optimisation problem satisfies assumptions (1) to (3) in section (2.2), then from Eberly and Van Mieghem (1997) the optimal investment strategy for each line of capital can be characterised by the investment and disinvestment demand triggers $U$ and $L$. For a level of demand just below the current investment threshold $U^{*}$, which is a function of the distribution of current demand shocks, we can model the return from a marginal investment for each line of capital in terms of investing this period versus investing next period:

\footnotetext{
${ }^{23}$ The timing assumptions are that the firm invests then experiences a demand shock each period.
} 
Investment This Period: $R_{K}(K, P) \Delta t-B+\gamma \int_{-\infty}^{\infty} V_{K}(K, P) d F(P)$

$$
\text { Investment Next Period: } \gamma \int_{U}^{\infty}\left(V_{K}(K, P)-B\right) d F(P)
$$

where the integral is taken with respect to $F(P)$, the cumulative probability distribution of current demand shocks. At the investment margin $U^{*}$ these two returns will be equal and we can combine them to write:

$$
R_{K}\left(K, U^{*}\right) \Delta t-B(1-\gamma)-\gamma \int_{-\infty}^{U}\left(B-V_{K}(K, P)\right) d F(P)=0
$$

This first two terms can be interpreted as the marginal returns to investment in the current period, $R_{K}\left(K, U^{*}\right) \Delta t$, less the cost of capital $B(1-\gamma)$ on paying

for investment this period rather than next period. The last term, $\gamma \int_{-\infty}^{U}(B-$ $\left.V_{K}(K, P)\right) d F(P)$, is equal to the value of a put option on a marginal investment next period with a strike price of $B$. Since the value of this put option must be positive, and the marginal revenue product is concave, the investment threshold this period will be above its reversible level.

Similarly we can also frame the marginal disinvestment decision at the current lower trigger $L^{*}$ in terms of disinvesting this period versus for a capital resale price of $S$ versus waiting until next period

\section{Disinvestment This Period: $S$}

Disinvestment Next Period: $R_{K}(K, P) \Delta t+\gamma \int_{-\infty}^{L} S d F(P)+\gamma \int_{L}^{\infty} V_{K}(K, P) d F(P)$ 
At this period's disinvestment margin $L^{*}$ these two returns will be equal and we can write

$$
R_{K}\left(K, L^{*}\right) \Delta t-S(1-\gamma)+\gamma \int_{L}^{\infty}\left(V_{K}(K, P)-S\right) d F(P)=0
$$

This firm two terms can be interpreted as the one period marginal returns to delaying the disinvestment decision one period, whilst the last term, $\gamma \int_{L}^{\infty}\left(V_{K}(K, P)-\right.$ $S) d F(P)$, is equal to the value of a call option on a marginal disinvestment next period with a strike price of $S$. Since the value of this call option must be positive the disinvestment threshold will be below its reversible level.

In proceeding we will use the following notation $G(P)=\int_{-\infty}^{P}\left(F_{B}(X)-F_{A}(X)\right) d X$ to simplify exposition. It can be shown that an equivalent definition of second order stochastic dominance ${ }^{24}$ of $F_{A}$ over $F_{B}$ is that $G(P) \geq 0 \forall P$. The following Lemma will prove useful

\section{Lemma 1:}

$$
\int_{-\infty}^{\infty} V_{K}(K, P)\left(d F_{B}(P)-d F_{A}(P)\right)=\int_{L}^{U} V_{K P P}(K, P) G(P) d P
$$

Proof:

$$
\begin{aligned}
\int_{-\infty}^{\infty} V_{K}(K, P)\left(d F_{B}(P)-d F_{A}(P)\right)= & {\left[V_{K}(K, P)\left(F_{B}(P)-F_{A}(P)\right)\right]_{-\infty}^{\infty} } \\
& -\int_{-\infty}^{\infty} V_{K P}(K, P)\left(F_{B}(P)-F_{A}(P)\right) d P \\
= & -\int_{-\infty}^{\infty} V_{K P}(K, P)\left(F_{B}(P)-F_{A}(P)\right) d P \\
= & -\left[V_{K P}(K, P) G(P)\right]_{-\infty}^{\infty} \\
& +\int_{-\infty}^{\infty} V_{K P P}(K, P) G(P) d P
\end{aligned}
$$

\footnotetext{
${ }^{24}$ See, for example, Rothschild and Stiglitz (1970).
} 


$$
=\int_{L}^{U} V_{K P P}(K, P) G(P) d P
$$

The first and third lines follow by Riemann-Stieltjes integration by parts, and the second and fourth lines follow by the fact that ${ }^{25}$

$$
\begin{array}{|lllll|}
\hline V_{K}(K, P)=B & \text { and } & V_{K P}(K, P)=0 & \text { if } & P>U \\
S \leq V_{K}(K, P) \leq B & \text { and } & V_{K P}(K, P)>0 & \text { if } & L \leq P \leq U \\
V_{K}(K, P)=S & \text { and } & V_{K P}(K, P)=0 & \text { if } & L<P \\
\hline
\end{array}
$$

so that $V_{K P}(K, P)$ and $V_{K P P}(K, P)$ are zero outside the region of inaction.

At the investment threshold we take a total difference of (6.3) allowing the distribution of this period's demand shocks to change and this period's investment threshold to change but holding everything else from next period on constant. This allows us to examine the impact of a short run change in uncertainty on the current investment thresholds. This total difference can be written as,

$$
R_{K P}(K, U) d U^{*}-\gamma \int_{-\infty}^{U}\left(B-V_{K}(K, P)\right)\left(d F_{B}(P)-d F_{A}(P)\right)=0
$$

The second term is positive for a distribution $F_{B}$ which is second order stochastically dominated by $F_{A}$, but which has equal or lesser expected marginal value (i.e. that is $\left.\int_{-\infty}^{\infty} V_{K}(K, P)\left(d F_{B}(P)-d F_{A}(P)\right) \leq 0\right)$. To see this expand this second term using integration by parts

$$
\begin{aligned}
\int_{-\infty}^{U}\left(B-V_{K}(K, P)\right)\left(d F_{B}(P)-d F_{A}(P)\right)= & {\left[\left(B-V_{K}(K, P)\right)\left(F_{B}(P)-F_{A}(P)\right)\right]_{-\infty}^{U} } \\
& \left.+\int_{-\infty}^{U} V_{K P}(K, P)\right)\left(F_{B}(P)-F_{A}(P)\right) d P \\
= & \left.\int_{-\infty}^{U} V_{K P}(K, P)\right)\left(F_{B}(P)-F_{A}(P)\right) d P
\end{aligned}
$$

\footnotetext{
${ }^{25}$ See the characterisation of the optimal investment strategy in section (2.2) in the main body of the paper or in Eberly and Van Mieghem (1997).
} 


$$
\begin{aligned}
= & {\left.\left[V_{K P}(K, P)\right) G(P)\right]_{-\infty}^{U} } \\
& -\int_{-\infty}^{U} V_{K P P}(K, P) G(P) d P \\
= & V_{K P}(K, U) G(U) \\
& \left.-\int_{L}^{U} V_{K P P}(K, P)\right) G(P) d P \\
\geq & 0 \text { if } \int_{-\infty}^{\infty} V_{K}(K, P)\left(d F_{B}(P)-d F_{A}(P)\right) \leq 0
\end{aligned}
$$

The first and third lines follow by Riemann-Stieltjes integration by parts; the second line follows because $F_{A}(-\infty)=F_{B}(-\infty)=0$ and $V_{K}(K, U)=B$; the fourth line follows because $\int_{-\infty}^{-\infty}\left(d F_{B}(X)-d F_{A}(X)\right) d X=0$ and $V_{K P P}(K, P)=0$ if $P<L$; while the fifth line follows because $G(U) \geq 0$ by stochastic dominance of $F_{A}$ over $F_{B}$ and by Lemma 1.

Hence, we can write that

$$
\begin{aligned}
d U^{*} & \left.=\frac{\gamma}{R_{K P}\left(K, U^{*}\right)}\left(V_{K P}(K, U)\right) G(U)-\int_{L}^{U} V_{K P}(K, P) G(P) d P\right) \\
& \geq 0 \text { if } \int_{-\infty}^{\infty} V_{K}(K, P)\left(d F_{B}(P)-d F_{A}(P)\right) \leq 0
\end{aligned}
$$

At the disinvestment threshold we take a total difference of (6.6) allowing the distribution of future demand shocks and the disinvestment threshold to change, and by similar arguments we can derive

$$
\begin{aligned}
d L^{*} & \left.\left.=\frac{\gamma}{R_{K P}\left(K, L^{*}\right)}\left(-V_{K P}(K, L)\right) G(L)+\int_{L}^{U} V_{K P}(K, P)\right) G(P) d P\right) \\
& \leq 0 \text { if } \int_{-\infty}^{\infty} V_{K}(K, P)\left(d F_{B}(P)-d F_{A}(P)\right) \geq 0
\end{aligned}
$$

So that for a change in distribution from $F_{A}$ to $F_{B}$ whereby the latter is stochastically dominated by the former but they both yield the same expected marginal value of capital, so that $\int_{-\infty}^{\infty} V_{K}(K, P)\left(d F_{B}(P)-d F_{A}(P)\right)=0$, the investment 
threshold will move up and the disinvestment threshold will move down. Combining these two conditions (6.7) and (6.8) and imposing condition (3) from section (2.2), we find that $R_{K P}\left(K, U^{*}\right)=R_{K P}\left(K, L^{*}\right)$ by the multiplicative nature of the demand shock in the revenue function, so that

$$
\begin{aligned}
d U^{*}-d L^{*} & =\frac{\gamma}{R_{K P}\left(K, U^{*}\right)}\left(V_{K P}(K, U) G(U)-V_{K P}(K, L) G(L)\right) \\
& \geq 0
\end{aligned}
$$

for any $F_{B}$ which is stochastic dominated by $F_{A}$ regardless of whether $\int_{-\infty}^{\infty} V_{K}(K, P)\left(d F_{B}(P)-\right.$ $\left.d F_{A}(P)\right)$ is positive or negative. Since this holds without loss of generality for every line of capital in a multi-line of capital revenue function we obtain the necessary result.

\section{Proof of Proposition 2}

With costless reversibility the firm's revenue $R\left(K_{1}, K_{2} . . K_{N}, P\right)$ is equal to current sales, $Y\left(K_{1}, K_{2}, \ldots K_{N}, P\right)$, less capital costs $\sum_{i}(r+\delta)_{i} K_{i}$

$$
R\left(K_{1}, K_{2} . . K_{N}, P\right)=Y\left(K_{1}, K_{2}, \ldots K_{N}, P\right)-\sum_{i}(r+\delta)_{i} K_{i}
$$

The first order conditions for profit maximisation are

$$
\partial Y\left(K_{1}, K_{2}, \ldots K_{N}, P\right) / \partial K_{i}=(r+\delta)_{i} \quad i=1,2 \ldots N
$$

Using the property that $Y\left(K_{1}, K_{2} . . K_{N}, P\right)$ is jointly homogeneous of degree one in $\left(K, P^{\frac{1}{1-\lambda}}\right)$, so that $\partial Y\left(K_{1}, K_{2} . . K_{N}, P\right) / \partial K_{i}$ is jointly homogeneous of degree zero in $\left(K, P^{\frac{1}{1-\lambda}}\right)$, these can be restated in matrix form as 


$$
\begin{gathered}
\partial Y\left(K_{1} P^{-\frac{1}{1-\lambda}}, K_{2} P^{-\frac{1}{1-\lambda}}, \ldots K_{N} P^{-\frac{1}{1-\lambda}}, 1\right) / \partial K_{1}=(r+\delta)_{1} \\
\partial Y\left(K_{1} P^{-\frac{1}{1-\lambda}}, K_{2} P^{-\frac{1}{1-\lambda}}, \ldots K_{N} P^{-\frac{1}{1-\lambda}}, 1\right) / \partial K_{2}=(r+\delta)_{2} \\
\ldots \\
\ldots \\
\partial Y\left(K_{1} P^{-\frac{1}{1-\lambda}}, K_{2} P^{-\frac{1}{1-\lambda}}, \ldots K_{N} P^{-\frac{1}{1-\lambda}}, 1\right) / \partial K_{N}=(r+\delta)_{N}
\end{gathered}
$$

which represents $N$ equations for $\partial Y / \partial K_{1}, \partial Y / \partial K_{2}, \ldots \partial Y / \partial K_{N}$ in the $N$ unknowns $K_{1} P^{-\frac{1}{1-\lambda}}, K_{2} P^{-\frac{1}{1-\lambda}}, \ldots . K_{N} P^{-\frac{1}{1-\lambda}}$. Since $Y\left(K_{1}, K_{2} . . K_{N}, P\right)$ is continuously differentiable it is a continuously differentiable mapping from $\mathbb{R}^{N} \rightarrow \mathbb{R}^{1}$. Furthermore, $Y\left(K_{1}, K_{2} . . K_{N}, P\right)$ is strictly concave so that the matrix of second derivatives with respect to capital $Y_{K K}\left(K_{1}, K_{2} . . K_{N}, P\right): \mathbb{R}^{N} \rightarrow \mathbb{R}^{N}$ will have full rank. Hence, we can use the inverse function theorem to write

$$
\begin{gathered}
K_{1} P^{-\frac{1}{1-\lambda}}=h_{1}\left((r+\delta)_{1},(r+\delta)_{1}, \ldots(r+\delta)_{N}\right) \\
K_{2} P^{-\frac{1}{1-\lambda}}=h_{2}\left((r+\delta)_{1},(r+\delta)_{1}, \ldots(r+\delta)_{N}\right) \\
\ldots \\
\ldots \\
K_{N} P^{-\frac{1}{1-\lambda}}=h_{N}\left((r+\delta)_{1},(r+\delta)_{1}, \ldots(r+\delta)_{N}\right)
\end{gathered}
$$

Defining $A_{i}=h_{i}\left((r+\delta)_{1},(r+\delta)_{1}, \ldots(r+\delta)_{N}\right)$ this can be re-written as

$$
K_{i}=A_{i} P^{\frac{1}{1-\lambda}}, \quad i=1,2, \ldots . N \quad \text { some } A_{i} \in \mathbb{R}^{1}
$$

so that $\sum K_{i}=P^{\frac{1}{1-\lambda}} \sum A_{i}$, which can be stated in logs as,

$$
\log \left(\sum K_{i}\right)=\log \left(\sum A_{i}\right)+\frac{1}{1-\lambda} \log P
$$

Using the result (6.13) in writing out the sales function we obtain

$$
\begin{aligned}
Y\left(K_{1}, K_{2}, \ldots K_{N}, P\right) & =Y\left(A_{1} P^{\frac{1}{1-\lambda}}, A_{2} P^{\frac{1}{1-\lambda}}, \ldots A_{N} P^{\frac{1}{1-\lambda}}, P\right) \\
& =P^{\frac{1}{1-\lambda}} Y\left(A_{1}, A_{2}, \ldots A_{N}, 1\right)
\end{aligned}
$$


where the second line follows by homogeneity. Hence, taking logs and using (6.14) to substitute out $\frac{1}{1-\lambda} \log P$ delivers

$$
\log \left(\sum K_{i}\right)=\log \frac{\left(\sum A_{i}\right)}{Y\left(A_{1}, A_{2}, \ldots A_{N}, 1\right)}+\log Y\left(K_{1}, K_{2}, \ldots K_{N}, P\right)
$$

\section{Appendix B: Data}

The UK data is taken from the published accounts of manufacturing firms listed on the UK stock market. We deleted firms with less than three consecutive observations, broke the series for firms whose accounting period fell outside 300 to 400 days due to changes in year end timing, and excluded the observations for firms where there are jumps of greater than $150 \%$ in any of the variables. This data is obtained from the Datastream on-line service.

Investment $(I)$. Total new fixed assets less fixed asset sales: DS435-DS423.

Capital Stock $(K)$ : Constructed by applying a perpetual inventory procedure with a depreciation rate of $8 \%$. The starting value was based on the net book value of tangible fixed capital assets in the first observation within our sample period, adjusted for previous years inflation. Subsequent values were obtained using accounts data on investment and asset sales, and an aggregate series for investment goods prices.

Sales $(Y)$ : Total sales, DS104, deflated by the aggregate GDP deflator.

Cash Flow $(C)$ : Net profits (earned for ordinary), DS182, plus depreciation, DS136.

Uncertainty $(\sigma)$. The computation of this variable is described in the text. For a company we take the daily stock market return (Datastream Returns Index, RI). This measure includes on a daily returns basis the capital gain on the 
stock, dividend payments, the value of rights issues, special dividends, and stock dilutions. We then compute the standard deviation of these daily returns on a year by year basis matched precisely to the accounting year, and adjust for the firm's debt-equity ratio as in Leahy and Whited (1998). We trim the variable so that values above five are set equal to five. The results are robust to dropping these ten observations.

\section{Appendix C: Estimation with Simulated Invest- ment Data}

The simulated data is based on the canonical investment model outlined in section (2). It is generalised to allow for partially irreversible labour as well as capital. It incorporates aggregation by assuming that the firms operate a number of production plants which experience both idiosyncratic plant level shocks and common firm level shocks. This procedure generates lumpy plant-level investment and employment data and smoother firm-level investment and employment data. For the US Compustat data base, this simulated firm-level data appears to closely parallel the main time series and cross sectional properties of actual firm-level data (see Bloom 2000b). This simulation method is outlined below.

Plants are assumed to have a Cobb-Douglas revenue function, $P K^{a} L^{b}$, where $P$ is a demand term, $K$ is capital, $L$ is labour and $0<a+b<1$. Both factors are assumed to be partially irreversible. Demand is stochastic with $P$ evolving as a Brownian motion process. This Brownian motion process can be broken down into two Brownian sub-components. The first is an observable firm-level shock which is common to all plants. The second is an idiosyncratic plant-level shock which 
is independent across plants and has a zero mean ${ }^{26}$. These plant-level shocks are assumed to be unobservable in our firm-level data set.

For this framework Eberly and Van Mieghem (1997) prove that the optimal investment and employment thresholds for each plant can be modelled according to the threshold rules laid out in Table AI. Investment only occurs when the marginal revenue product of capital, $a P K^{a-1} L^{b}$, is equal to its investment user cost of capital, $b$, times an investment real options term, $\phi_{I}^{K}>1$. And disinvestment only occurs when the marginal revenue product falls to its disinvestment cost of capital, $s$, divided by a disinvestment real options term, $\phi_{D}^{K}>1$. In between these thresholds the plant will undertake no investment or disinvestment. We can characterise the hiring and firing thresholds similarly in terms of the marginal revenue product of labour, $b A K^{a} L^{b-1}$, the present discounted costs of hiring one worker, $h$, the present discounted savings from firing one worker, $f$, and the hiring and firing real options terms, $\phi_{H}^{L}>1$ and $\phi_{F}^{L}>1$ respectively ${ }^{27}$.

Table AI: The Simulation Thresholds for Investment and Hiring

\begin{tabular}{|lr|lr|}
\hline Invest if & $a A K^{a-1} L^{b} \geq b \times \phi_{I}^{K}$ & Hire if & $b A K^{a} L^{b-1} \geq h \times \phi_{H}^{L}$ \\
\hline Do Nothing & $s / \phi_{L}^{K}<a A K^{a-1} L^{b}<b \times \phi_{I}^{K}$ & Do Nothing & $f / \phi_{F}^{L}<b A K^{a} L^{b-1}<h \times \phi_{H}^{L}$ \\
\hline Disinvest if & $a A K^{a-1} L^{b} \leq s / \phi_{D}^{K}$ & Fire if & $b A K^{a} L^{b-1} \leq f / \phi_{F}^{L}$ \\
\hline
\end{tabular}

These real options terms can be numerically calculated given our assumptions on the parameters in the firm's environment - the discount rate $(10 \%)$, the revenue function parameters $(a=0.25$ and $b=0.5)$, the ratio of $b / s=0.5$ and

\footnotetext{
${ }^{26}$ The plant level shock can always be defined to have a zero mean through the definition of the firm level shock as the average plant level shock in each period. The assumption that the plant level shocks are independent across plans can be weakened to imperfect correlation across plants, and is made for the simplicity of the simulation exercise.

${ }^{27}$ Where $h>f>0$ because hiring and firing both involve costs which are not recouped.
} 
$h / f=0.9$. These parameters are chosen to match survey evidence on production functions, the cost of capital (see, for example, Summers (1987)) and the low rates of disinvestment at the firm level. The labour hiring/firing prices were chosen as economically reasonable values (see, for example, Nickell (1986)) which also provide a good fit between actual and simulated data.

Finally, we proxy the firm specific degree of uncertainty by using the mean standard deviation of the firm's daily share returns, $\sigma_{i}$, over our sample period ${ }^{28}$. This measure of uncertainty is here defined so as to be time invariant in line with Eberly and Van Mieghem's (1997) modelling assumptions.

The firm-level demand shock is proxied for by the growth in real firm sales. For each firm we also need to start with an initial distribution of projects between these investment, disinvestment, hiring and firing thresholds. This is generated by starting all projects as identical and running the simulation for twenty years to obtain an empirical ergodic distribution, which is then assumed to be the initial distribution we use to generate our simulated data ${ }^{29}$. Our simulated firm level investment and hiring data is then calculated by adding up across all plants within each firm. In these simulations we assumed all firms operate 20 plants $^{30}$.

In Table AII we present the results from GMM estimation of error correction models using the simulated capital stock and investment data, $K^{S}$ and $\left(\frac{I^{S}}{K^{S}}\right)$

\footnotetext{
${ }^{28}$ These values are divided by 5 here to re-scale them in line with the magnitudes of annual sales and price variation.

${ }^{29}$ Not surprisingly, this assumption leads to violations of the initial conditions restrictions required by the System GMM estimator we use in our main empirical analysis. For this reason we present results for the simulated data using only equations in first differences, for which lagged levels of the variables are used as instruments.

${ }^{30}$ Perhaps surprisingly, the number of plants we assume that operate within each firm appears to make very little difference to our panel estimation results. The simulated results derived assuming firms operate 2 or 200 plants look almost identical to those presented in Table AII using 20 plants.
} 
respectively, and the actual sales data used to generate this. The sample is exactly the same as that used to estimate our results in Tables 7 and 8 in the main text. 
Table AII: GMM Estimates Using The Simulated Investment Data

\begin{tabular}{|l|c|c|c|c|}
\hline Dependent Variable $\left(I_{t}^{S} / K_{t-1}^{S}\right)$ & $\mathbf{( 1 )}$ & $\mathbf{( 2 )}$ & $\mathbf{( 3 )}$ & $\mathbf{( 4 )}$ \\
\hline Sales Growth $\left(\Delta y_{i t}\right)$ & 0.501 & 0.412 & 0.317 & 0.461 \\
\hline & $(0.038)$ & $(0.026)$ & $(0.025)$ & $(0.072)$ \\
\hline Error Correction Term $\left(y-k^{S}\right)_{i, t-1}$ & & 0.274 & 0.263 & 0.266 \\
\hline & & $(0.024)$ & $(0.021)$ & $(0.011)$ \\
\hline Sales Growth Sqrd. $\left(\Delta y_{i t} * \Delta y_{i t}\right)$ & & & 0.453 & 0.446 \\
\hline & & & $(0.062)$ & $(0.060)$ \\
\hline Uncert. $\times$ Sales Growth $\left(\sigma_{i} * \Delta y_{i t}\right)$ & & & & -0.085 \\
\hline & & & & $(0.041)$ \\
\hline \hline 2nd order serial correlation $(\mathrm{p})$ & 0.000 & 0.758 & 0.223 & 0.231 \\
\hline Sargan $(\mathrm{p})$ & 0.000 & 0.252 & 0.127 & 0.214 \\
\hline
\end{tabular}

NOTES:- The total number of observations (for all columns) is 5347, on a sample period of 1973 to 1991, with 672 firms. A full set of time dummies is included in every specification. Estimation uses a first-differenced GMM estimator computed in DPD98 for Gauss (see Arellano and Bond, 1998). One step coefficients and heteroskedasticity-consistent standard errors are reported. The instruments used for all equations are lags two and three of the variables: $\left(\frac{I^{S}}{K^{S}}\right)_{i, t-2}$ and $\left(\frac{I^{S}}{K^{S}}\right)_{i, t-3}, \Delta y_{i, t-2}$ and $\Delta y_{i, t-3},(y-k)_{i, t-2}$ and $(y-k)_{i, t-3}$, and $\sigma_{i}$. Instrument validity is tested using a Sargan-Hansen test of the overidentifying restrictions for the two step GMM estimator. The test for no second order serial correlation in the first-differenced residuals is also reported.

The high degree of residual autocorrelation in the static accelerator specification of column (1) and the failure of the Sargan test is testament to the strong dynamics in this simulated data arising from the lagged effect of demand shocks on investment though 'pent up demand'. In column (2) we include a lagged error correction term which reflects the deviation of the firm's capital/output ratio from its long run level. This removes the finding of significant second order serial correlation in the first-differenced residuals, and the Sargan test does not reject this specification. In column (3) we add in the squared sales growth term, which is found to be positive and highly significant. Our test thus correctly rejects the null hypothesis of a linear relationship between investment rates and sales growth, 
and the convex relationship detected is that predicted in section (2.4.1).

Finally, in column (4) we also include the interaction term between sales growth and uncertainty. This interaction term is found to be negative and significant at the 5\% level. Again our empirical test correctly rejects the null hypothesis of a common response to demand shocks for high uncertainty and low uncertainty firms, and we detect the predicted weaker response of investment to demand shocks at higher levels of uncertainty.

We conclude that if the data were generated by a partial irreversibility model, our empirical tests should be able to reject the linear error correction specification, and the inclusion of quadratic and interaction terms should detect the correct signs on these additional variables. 


\section{References}

ABEL, A. and EBERLY, J. (1994), "A unified model of investment under uncertainty", American Economic Review, 84, 1369-1384.

ABEL, A. and EBERLY, J. (1995), "The Effects of Irreversibility and Uncertainty on Capital Accumulation", NBER Working Paper no. 5363.

ABEL, A. and EBERLY, J. (1996), "Optimal Investment with Costly Reversibility", Review of Economic Studies, 63, 581-593.

ANDERSEN, T. and BOLLERSLEV, T. (1998), "Answering the Skeptics: Yes, Standard Volatility Models do Provide Accurate Forecasts", International Economic Review, 39, 885-905.

ANTI-NIELSEN, O. and SCHIANTARELLI, F. (1999), "Zeroes and Lumps in Investment: Empirical Evidence on Irreversibilities and Non-convexities", Working Paper in Economics No. 1198, University of Bergen.

ARELLANO, M. and BOND, S. (1991), "Some Tests of Specification for Panel Data: Monte Carlo Evidence and an Application to Employment Equations", Review of Economic Studies, 58, 277-297.

ARELLANO, M. and BOND, S. (1998), "DPD for Gauss: a Guide for Users", http:/www.ifs.org.uk/staff/steve_b.shtml.

ATTANASIO, O. REDUTO DOS REIS, I. and PACELLI, L. (2000), "Aggregate Implications of plant level investment behaviour: Evidence from the UK ARD", Institute for Fiscal Studies mimeo.

ATTANASIO, O. and PACELLI, L. (2000), "A Semi-Structural Model of Micro Investment Behaviour", IFS mimeo.

ATTANASIO, O. (2000), "Consumer Durables and Inertial Behavior: Estima- 
tion and Aggregation of Ss Rules for Automobiles", Review of Economic Studies, 67, 659-677.

BARTLE, R. (1966), The elements of integration and Lebesgue measure, Wiley Publishers, New York.

BEAN, C. (1981), "An econometric model of manufacturing investment in the UK", Economic Journal, 91, 106-121.

BERTOLA, G. (1988), "Irreversible Investment", Massachusetts Institute of Technology doctoral thesis, re-printed in Research in Economics (1998), 52, 3-37.

BERTOLA, G. and CABALLERO, R. (1994), "Irreversibility and Aggregate Investment", Review of Economic Studies, 61, 223-246.

BLOOM, N. (2000a), "The Real Options Effect of Uncertainty on Investment and Labour Demand", Institute for Fiscal Studies working paper W00/15.

BLOOM, N. (2000b), "The Dynamic Demand for Capital and Labour - modelling Real Options and Irreversibility", Institute for Fiscal Studies mimeo.

BLUNDELL, R. and BOND, S. (1998), "Initial Conditions and Moment Restrictions in Dynamic Panel Data Models", Journal of Econometrics, 87, 115-143.

BOND, S., HARHOFF, D. and VAN REENEN, J. (1999), "Investment, R\&D and financing constraints in Britain and Germany", IFS Working Paper no. W99/5. CABALlERO, R. (1999), "Aggregate investment", in: J.B. Taylor and M. Woodford, Eds., Handbook of Macroeconomics, vol. 1B (North-Holland, Amsterdam).

CABALLERO, R., ENGEL, E. and HALTIWANGER, J. (1995), "Plant-level adjustment and aggregate investment dynamics", Brookings Papers on Economic Activity, 95(2), 1-54. 
COOPER, R., HALTIWANGER, J. and POWER, L. (1999), "Machine Replacement and the Business Cycle: Lumps and Bumps", American Economic Review, 86, 921-946.

DAVIS, S. and HALTIWANGER, J. (1992), "Gross Job Creation, Gross Job Destruction, and Employment Reallocation", Quarterly Journal of Economics, 107, 819-863.

DIXIT, A. (1989), "Entry and Exit Decisions under Uncertainty". Journal of Political Economy, 97, 620-638.

DIXIT, A., and Pindyck, R. (1994), Investment Under Uncertainty, Princeton University Press, Princeton, New Jersey.

DIXIT, A. (1997), "Investment and Employment Dynamics in the Short Run and the Long Run", Oxford Economic Papers, 49, 1-20.

DOMS, M. and DUNNE, T., (1998), "Capital Adjustment Patterns in Manufacturing Plants", Review of Economic Dynamics, 1, 409-429.

EBERLY, J. and VAN MIEGHEM, J. (1997), "Multi-Factor Dynamic Investment under Uncertainty", Journal of Economic Theory, 75, 345-387.

FAZZARI, S., HUBBARD, R. and PETERSEN, B. (1988), "Financing constraints and corporate investment", Brookings Papers on Economic Activity, 141195.

GUISO, L. and PARIGI, G. (1999), "Investment and Demand Uncertainty", Quarterly Journal of Economics, 114, 185-227.

JENSEN, M. (1986), "Agency costs of free cash flow, corporate finance, and takeovers", American Economic Review, 76, 323-329.

LEAHY, J. and WHITED, T. (1998), "The Effects of Uncertainty on Invest- 
ment: Some Stylized Facts", Journal of Money Credit and Banking, 28, 64-83.

NICKELL, S. (1986), "Dynamic models of labor demand", in: O. Ashenfelter and R. Layard, Eds., Handbook of Labor Economics, vol.1 (North-Holland, Amsterdam).

PINDYCK, R. (1988), "Irreversible Investment, Capacity Choice, and the Valuation of the Firm", American Economic Review, 78, 969-985.

REDUTO DOS REIS, I. (1999), "Irreversible Investment and Fixed Costs. Evidence from ARD Establishment Level Data", University College London mimeo.

ROTHSCHILD, M. and STIGLITZ, J. (1970), "Increasing risk I: A definition", Journal of Economic Theory, 2, 225-243.

SUMMERS, L. (1987), Investment Incentives and the Discounting of Depreciation Allowances, In The Effects of Taxation of Capital Accumulation, ed. Martin Fieldstein. Chicago, IL: Chicago University Press.

WINDMEIJER, F. (1995) "A Note on $\mathrm{R}^{2}$ in the Instrumental Variables Model", Journal of Quantitative Economics, 11, 257-261. 
Figure 1. Aggregate Uncertainty in UK Manufacturing, 1972-1991

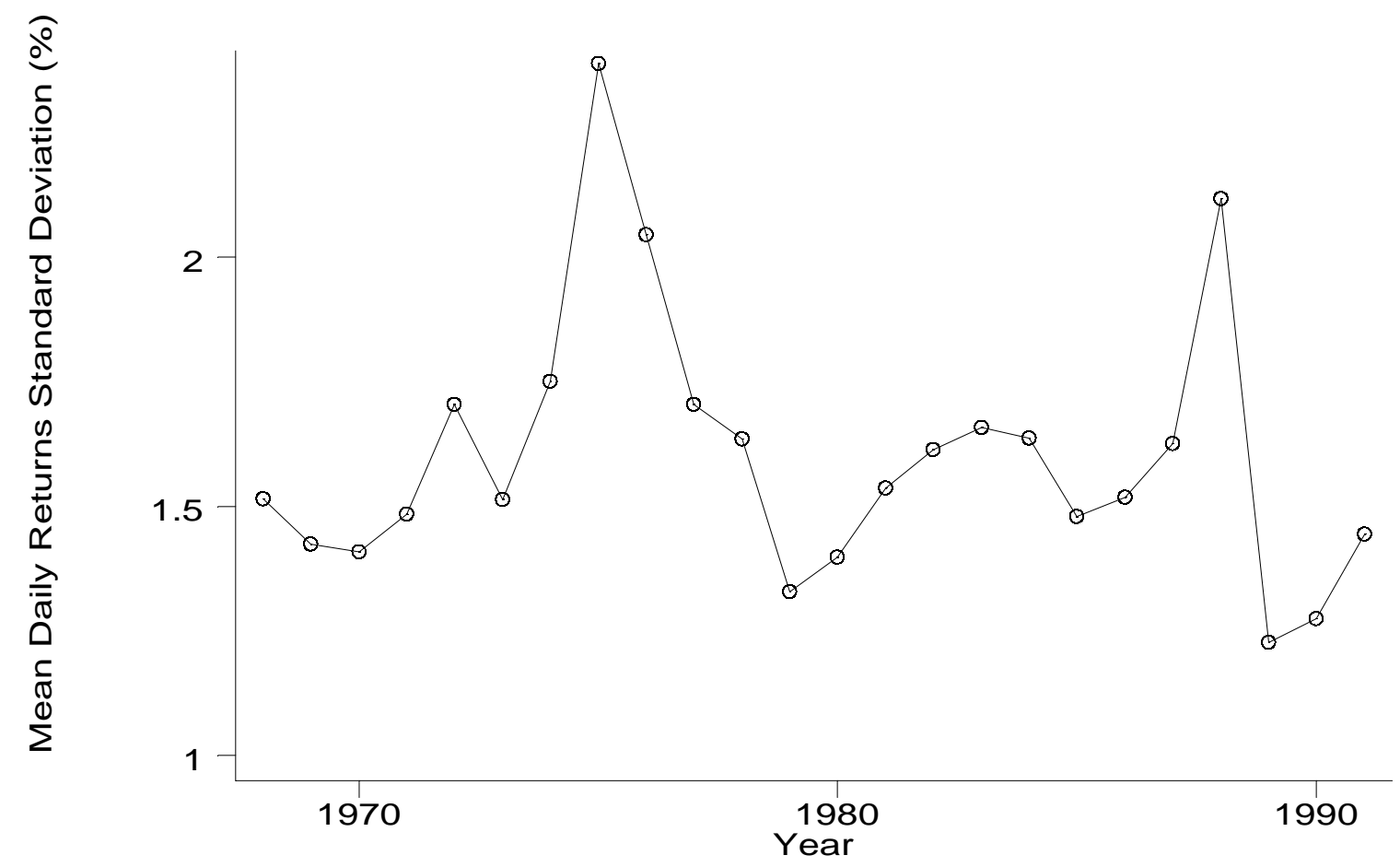

Notes: This is the uweighted mean of our measure of the standard deviation of daily returns over the year. 
Figure 2. The Investment Response to a $2.5 \%$ demand shock for the $10^{\text {th }}$, $25^{\text {th }}, \mathbf{5 0}$ th, $75^{\text {th }}$, and $90^{\text {th }}$ percentiles of uncertainty.

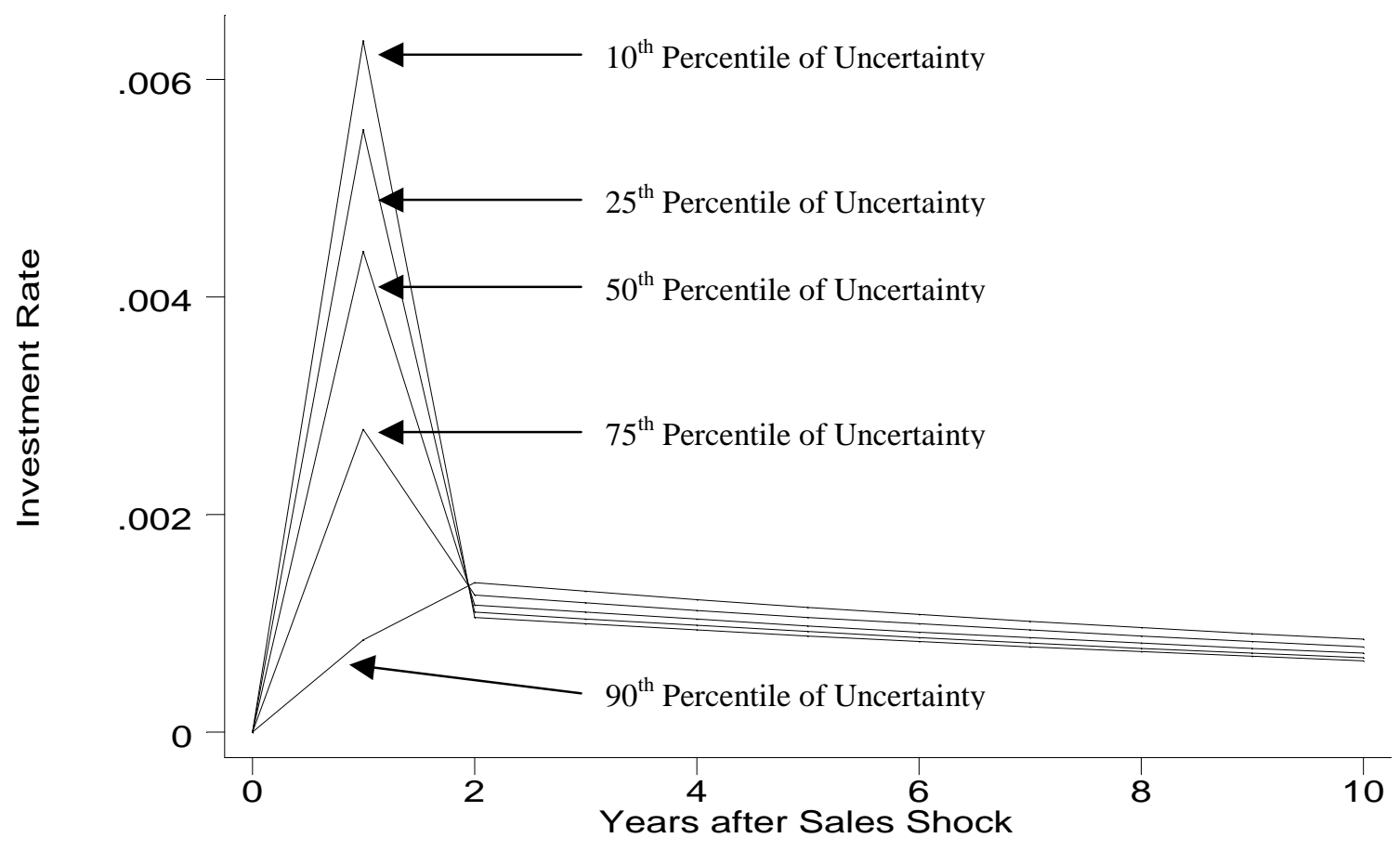

Notes: This simulates the firm-level investment response to a $2.5 \%$ demand shock using the parameters estimated in column (5) of Table 7 in the text. This response is plotted for the $10^{\text {th }}, 25^{\text {th }}, 50^{\text {th }}, 75^{\text {th }}$ and $90^{\text {th }}$ percentiles of the distribution of our measure of uncertainty. 


\section{Figure 3. The Capital Stock after a $2.5 \%$ demand shock for the $10^{\text {th }}, 25^{\text {th }}$, $50^{\text {th }},{75^{\text {th }}}^{\text {, and }} 90^{\text {th }}$ percentiles of uncertainty.}

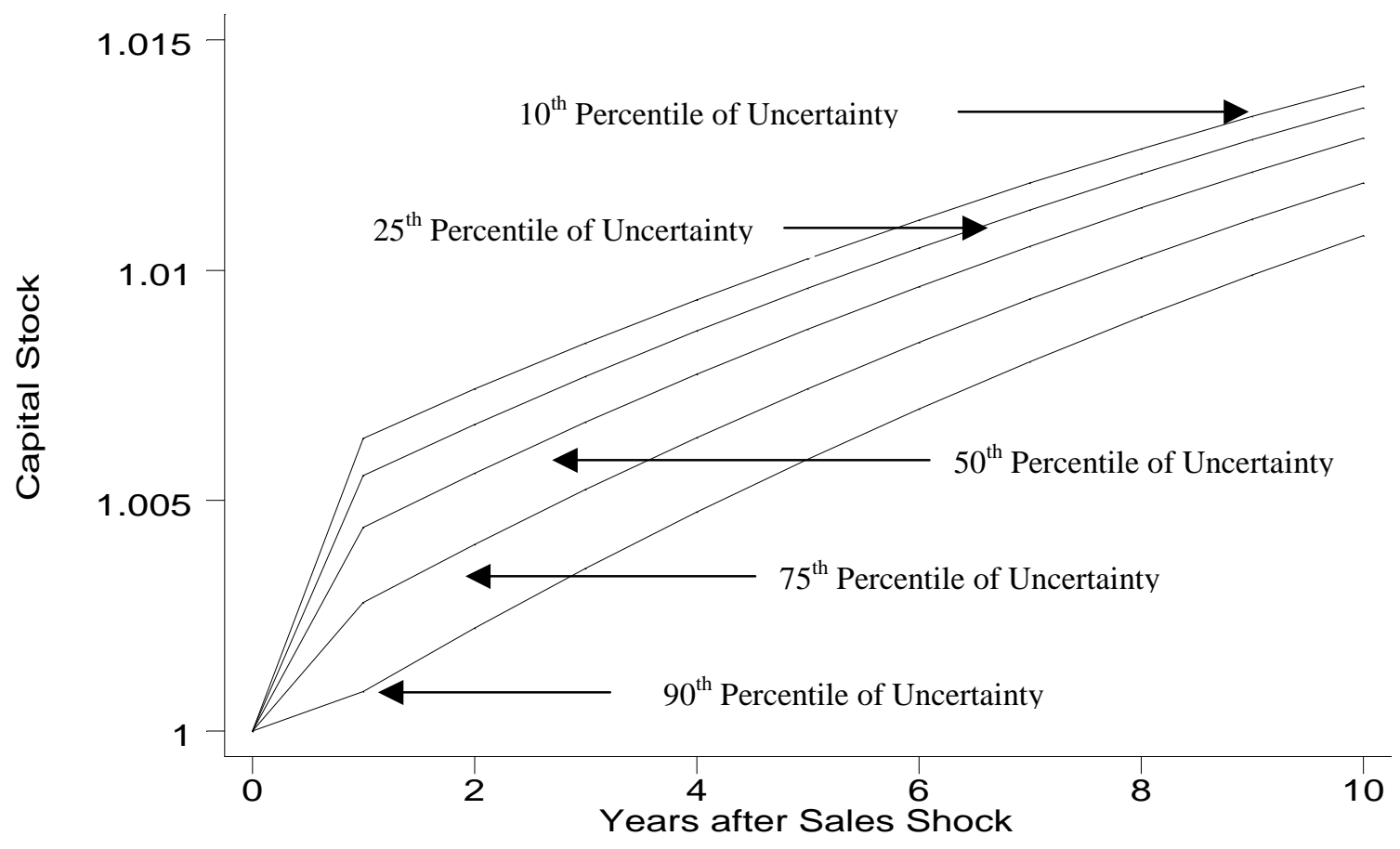

Notes: This simulates the firm-level capital stock after a $2.5 \%$ demand shock using the parameters estimated in column (5) of Table 7 in the text. This response is plotted for the $10^{\text {th }}, 25^{\text {th }}, 50^{\text {th }}, 75^{\text {th }}$ and $90^{\text {th }}$ percentiles of the distribution of our measure of uncertainty. 
Figure 4. Improvement in Fit From Adding an Uncertainty Interaction and Demand Squared Term (left axis), and Change of Growth Rate of Real Sales (right axis)

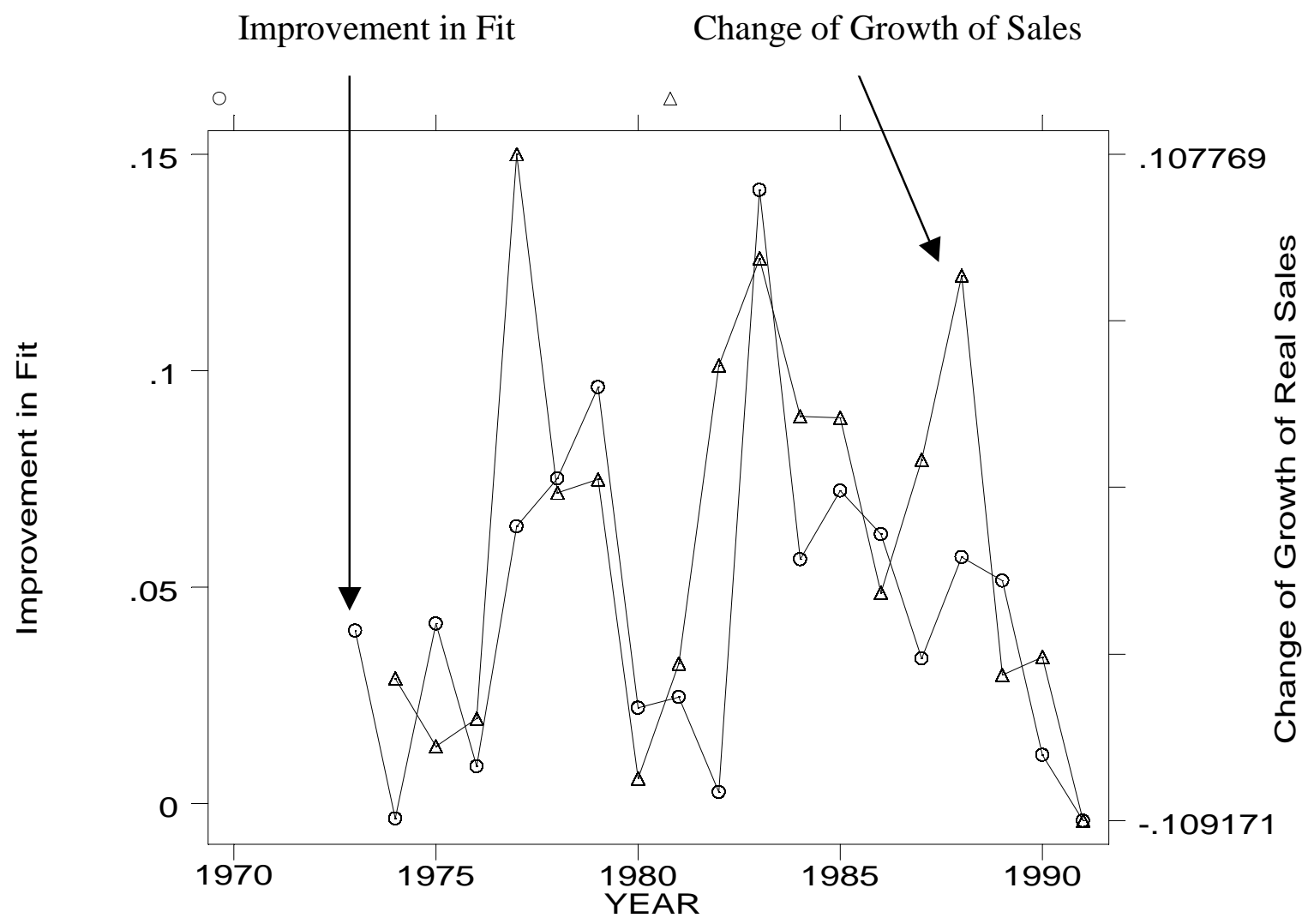

Notes: This graph plots on the left axis the year by year difference in correlation of actual investment rates with predicted investment rates using the uncertainty augmented model (column (5) of Table 7) and predicted investment rates using the standard model (column (1) of Table 7). Positive values represent an improvement in fit from using the uncertainty interaction term. Plotted on the right axis is the yearly average change of sales growth as an indicator of the business cycles turning points. 